\title{
Reducing barriers to accessing fistula repair in Nigeria and Uganda: An implementation research study
}

\author{
Pooja Sripad \\ Population Council \\ Elly Arnoff \\ Charity Ndwiga \\ Population Council \\ George Odwe \\ Population Council \\ Emmanuel Nwala \\ Population Council
}

Follow this and additional works at: https://knowledgecommons.popcouncil.org/departments_sbsr-rh How does access to this work benefit you? Let us know!

\section{Recommended Citation}

Sripad, Pooja, Elly Arnoff, Charity Ndwiga, George Odwe, and Emmanuel Nwala. 2020. "Reducing barriers to accessing fistula repair in Nigeria and Uganda: An implementation research study." Washington, DC: Population Council. 


\section{Acknowledgements}

We are grateful for the funding and support of USAID colleagues throughout this research-to-action effort and review of this report. We would like to acknowledge our partner, EngenderHealth. In particular, Vandana Tripathi for her support, collaboration, and technical feedback on this study, as well as Amina Bala and Ibrahim Haruna in Nigeria and Molly Tumusiime and Hasan Kanakulya in Uganda in for their active involvement in data collection, intervention implementation, and in-country support. We would also like to acknowledge Charlotte Warren for her feedback and oversight throughout the planning and implementation of this study. In addition, we thank Charles Nwaigwe, Karen Kirk, Gloria Adoyi, and Salisu Ishaku for their invaluable contributions to this work including but not limited to data collection and communications. Finally, we acknowledge and thank all of the individuals who participated in this study and generously shared their experience and opinions with us.

Suggested citation: Population Council. 2020. Reducing Barriers to Accessing Fistula Repair in Nigeria and Uganda: An Implementation Research Study. Washington, D.C.

The Population Council confronts critical health and development issues-from stopping the spread of HIV to improving reproductive health and ensuring young people lead full and productive lives. Through biomedical, social science, and public health research in 50 countries, we work with our partners to deliver solutions for more effective policies, programs, and technologies that improve lives around the world. Established in 1952 and headquartered in New York, the Council is a non-governmental, non-profit organization governed by an international board of trustees.

Population Council Washington

4301 Connecticut Avenue, NW

Suite 280

Washington, DC 20008

Tel: +1 2022379400

Fax: +1 2022378410

popcouncil.org 


\section{Contents}

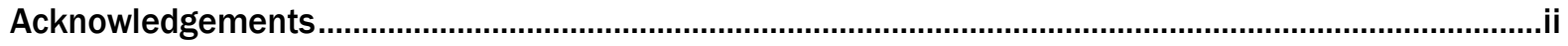

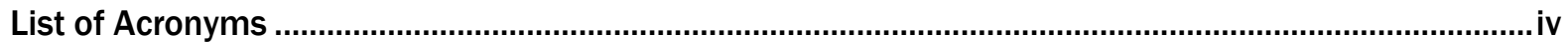

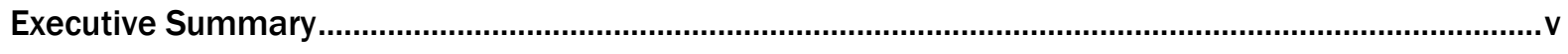

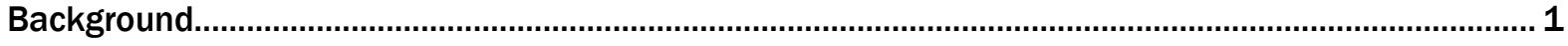

Study Aims

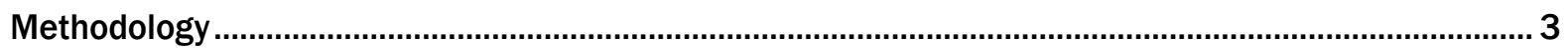

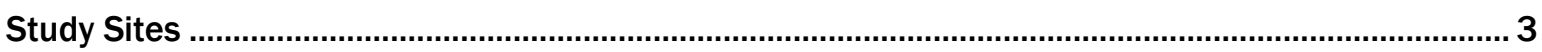

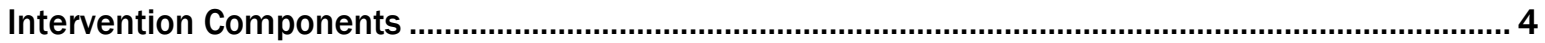

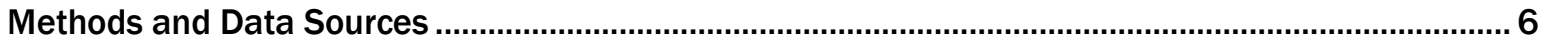

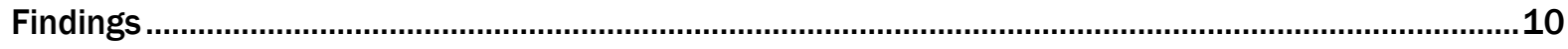

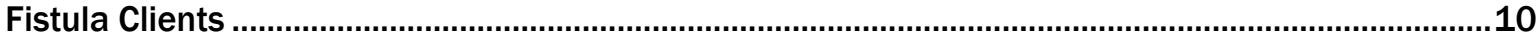

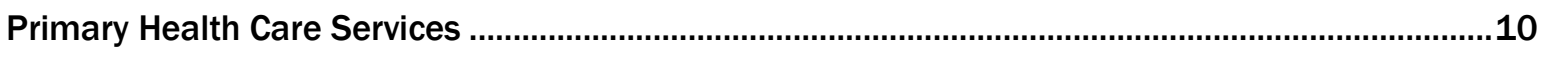

Implementation of a Comprehensive Intervention Affects Fistula Care-seeking, Diagnosis

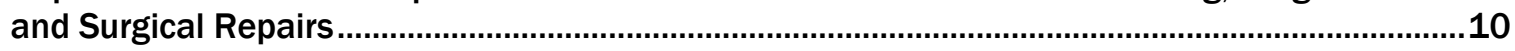

Digital Health Interventions and Transportation Vouchers Reduce Barriers to Fistula Care.........10

Focused Training and Job Aids Improve PHC Provider Abilities to Diagnose and Refer............. 210

Community Outreach Agents and Service Providers Effectively Promote an Efficicent, Community-based Referral Mechanism ........................................................................27

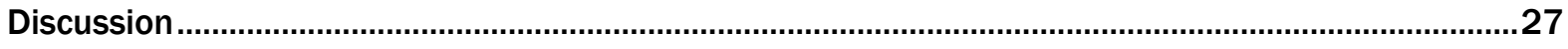

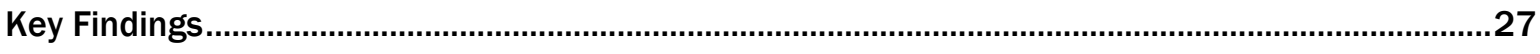

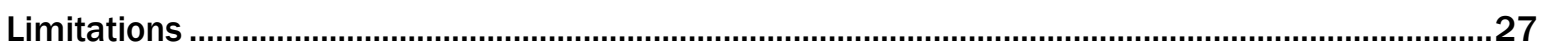

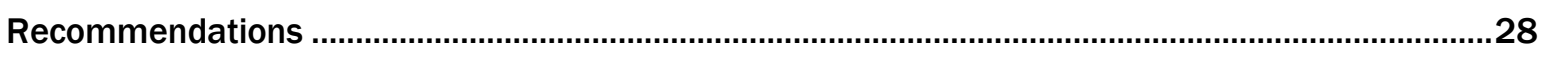

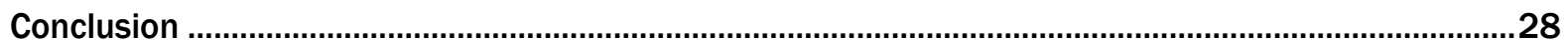

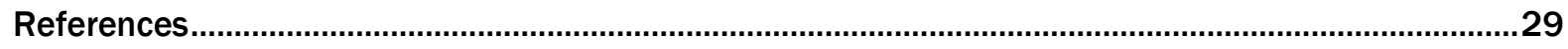

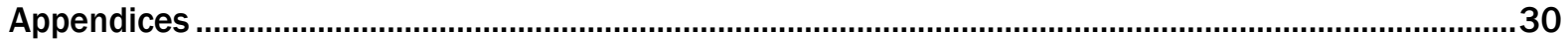




\title{
Acronyms
}

\author{
ANC Antenatal Care \\ CBO Community-based Organization \\ CHEW Community Health Extension Worker \\ CHO Community Health Officer \\ FC+ Fistula Care Plus \\ FGD Focus Group Discussion \\ IR Implementation Research \\ IVR Interactive Voice Response \\ LGA Local Government Area (Nigeria) \\ $\mathrm{MoH} \quad$ Ministry of Health \\ NOFIC National Obstetric Fistula Center, Abakaliki, Nigeria \\ OF Obstetric Fistula \\ PHC Primary Health Care \\ $\mathrm{P} / \mathrm{OL} \quad$ Prolonged or Obstructed Labor \\ Q Quarter (of calendar year) \\ RH Reproductive Health \\ SBC Social and Behavior Change \\ SMS Short Message Service \\ SPHCDA State Primary Health Care Development Agency (Nigeria) \\ USAID United States Agency for International Development \\ VHT Village Health Team
}




\section{Executive Summary}

Female genital fistula predominately affects women who are marginalized within their societies and lack access to quality maternal health care. While efforts to promote fistula identification and treatment exist, systematic knowledge about the barriers women face in accessing fistula treatment is lacking, in addition to rigorous evidence about interventions that effectively respond to these barriers. A research-to-action partnership between the Population Council and the USAID Fistula Care Plus (FC+) project implemented by EngenderHealth sought to understand and address critical barriers to fistula care in Nigeria and Uganda. This three-stage partnership comprised:

1. A global systematic review examining barriers to fistula treatment

2. Formative research in Nigeria and Uganda to better understand specific barriers experienced by women and identify potential responses, followed by

3. Implementation research (IR) to test evidence-informed solutions for reducing barriers to treatment.

The IR research study examined whether a comprehensive information, screening, and referral intervention in Uganda and Nigeria reduced transportation, communication, and financial barriers to preventive fistula care and improved its detection and treatment, focused on four fundamental questions:

1. Does implementation of a comprehensive intervention increase fistula care seeking, diagnosis, and surgical repairs?

2. Can digital health interventions and transportation vouchers reduce barriers to seeking and receiving fistula care?

3. Do focused training and job aids increase primary health care (PHC) providers' abilities to diagnose and refer?

4. How did community outreach agents and health care providers interact to promote an efficient, community-based referral system?

This IR study implemented a complex social behavior change (SBC) intervention featuring a single screening algorithm applied through multiple channels, in addition to free transportation, to promote women's improved access to fistula centers for diagnosis and treatment. A range of resources-a fistula screening hotline, communications materials, trainings for partners and implementers at different levels, job aids, transportation vouchers, as well as monitoring tools-and partners-including a digital health partner, community-based agents, community-based organizations, primary health center (PHC) providers, transportation providers, and health and social workers at fistula centers-were coordinated in three sites, in two states in Nigeria and one district in Uganda, to test the efficacy of the communitybased SBC intervention to improve fistula prevention, detection, and treatment.

A pre-post mixed method approach in the three sites collected quantitative data through facility assessments of three fistula centers and PHC centers ( $\mathrm{n}$ Ebonyi $=77, \mathrm{n}$ Katsina $=68$, $\mathrm{n}$ Uganda $=93$ ), PHC provider surveys ( $\mathrm{n}$ Ebonyi $=217, \mathrm{n}$ katsina $=181, \mathrm{n}$ uganda $=219$ ), post-repair fistula client surveys ( $\mathrm{n}$ Ebonyi $=142, \mathrm{n}$ katsina $=132, \mathrm{n}$ uganda $=143$ ), and program monitoring data, while qualitative data were collected through in-depth interviews (IDIs) with women living with fistula as well as intervention implementation stakeholders ( $\mathrm{n}$ Ebonyi $=60, \mathrm{n}$ katsina $=67, \mathrm{n}$ uganda $=65$ ), in addition to 34 focus group discussions (FGDs) with community members. 
This IR study finds that implementation of a complex SBC intervention is feasible in a controlled setting with sufficient resources, and effective when integrated within local, community-based health systems and partners. While the intervention process revealed implementation challenges, program participants concur on the importance of sustaining interventions that focus on fistula prevention and treatment.

The intervention's results demonstrate robust use of the screening hotline by community members and increased ability among women to seek fistula care through digital health solutions. The screening hotline and job aids supported community outreach agents in fistula screening and PHC provider referrals. Trainings provided by the intervention resulted in positive trends in fistula recognition and referral knowledge and practices among PHC providers and community agents.

Comprehensive communication strategies developed by the program engendered supportive community attitudes towards women living with fistula, including increased knowledge and support.

Increased fistula admissions and surgeries at fistula centers during the intervention, with concurrent reductions in awareness of barriers to treatment, in both comparison and intervention sites, suggest ancillary effects of a systems intervention, and evince the promise of wide-reaching digital health approaches, as part of a broader referral strategy for stigmatized populations such as women living with fistula. 


\section{Background}

Delays in seeking fistula repair are due to multiple factors, including insufficient knowledge and awareness both within communities and at their primary health care (PHC) facilities, in addition to financial and transportation barriers as well as weak links between community and facility referral systems, all of which have apparent significant impacts on treatment and access. Women may initially be unaware that their problem is medical, or even that repair is possible, and if they are aware of treatment options, may lack resources to seek care when distances to facilities are significant, with both travel and repair itself costly. Even if awareness, financial, and transportation barriers are overcome, women may face delays in appropriate care once at a facility, due to lack of skilled fistula surgeons and long hospital waits in low income countries. ${ }^{1,2}$

Female genital fistula is not only surgically treatable but preventable, but women who lack access to quality maternal health care often live with fistula for many years. Obstetric fistula, caused by inadequately managed, prolonged or obstructed labor $(\mathrm{P} / \mathrm{OL})$, is the most common type, yet iatrogenic fistula, caused by mistakes during cesarean section and hysterectomy, is increasing. For every 1,000 births, it has been estimated that 2.11 women develop fistula symptoms in Nigeria. ${ }^{3}$

In recent years, various initiatives have been established to both prevent and repair fistula. Despite accredited national fistula centers in Nigeria, most women with fistula remain unrepaired according to most estimates. In Uganda, while two percent and 1.4 percent of women in 2012 and 2016, respectively, reported having ever experienced fistula symptoms, 4,5 studies show persistent barriers to repair and effective reintegration. ${ }^{6-8}$

While numerous fistula service programs have promoted fistula case identification and treatment access, ${ }^{9-11}$ systematic knowledge about the barriers to women's access to fistula treatment is lacking, in addition to rigorous evidence about interventions that effectively respond to these barriers. To address these knowledge gaps, the Population Council and the USAID Fistula Care Plus (FC+) project implemented by EngenderHealth formed a research-to-action partnership to not only understand but address critical barriers to fistula care in Nigeria and Uganda. This three stage partnership comprised:

Stage One: A global systematic review examining barriers to fistula treatment

Stage Two: Formative research in Nigeria and Uganda to better understand specific barriers experienced by women and identify potential responses, and

Stage Three: Implementation research (IR) to test evidence-informed solutions to treatment barriers.
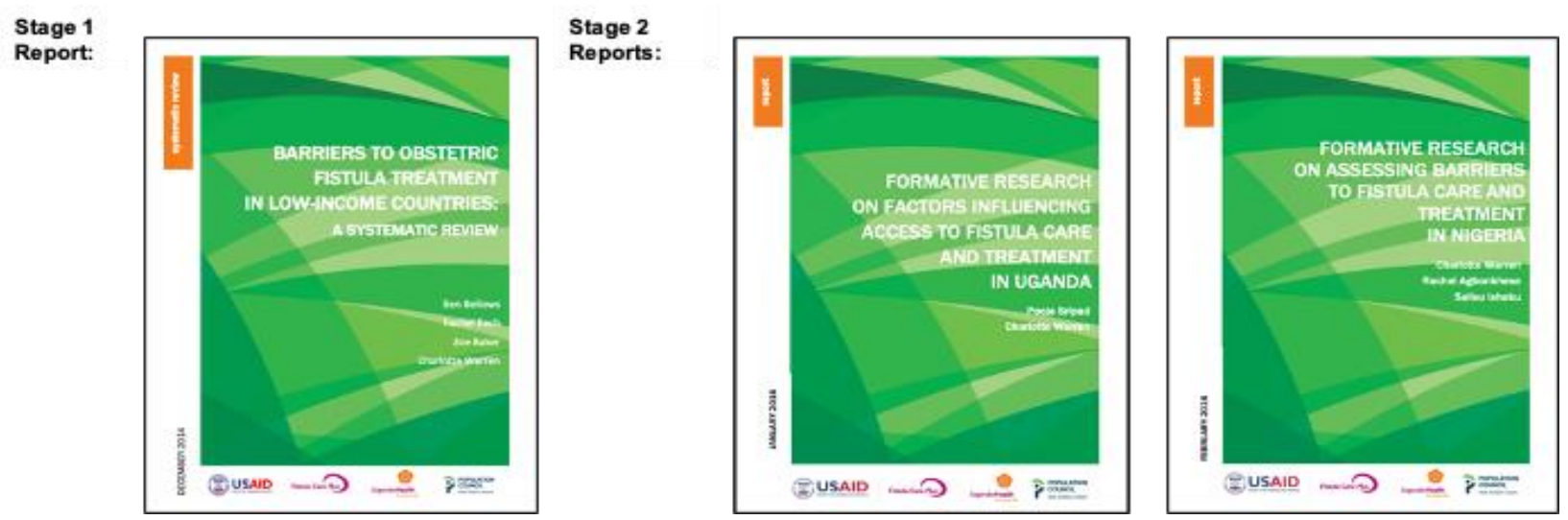
Findings from the first two stages informed the design of Stage Three, a comprehensive information, screening, and referral intervention that:

- Developed and activated multiple fistula information and screening channels, including an interactive voice response (IVR) hotline allowing women learn about fistula and determine their fistula statuses

- Increased health care provider and community outreach agent capacities for screening women for fistula to promote an efficient, community-based referral system linking women to fistula repair centers, and

- Developed and implemented a transportation voucher system to reduce fistula care center access barriers.

This study report describes the third stage of this research-to-action partnership, and assesses this comprehensive intervention that targeted both communities and facilities to reduce awareness and transportation barriers to fistula prevention, diagnosis, and repair. ${ }^{12}$

\section{Study Aims}

The Population Council and FC+ conducted IR to understand whether a comprehensive information, screening, and referral intervention reduces transportation, communication, and financial barriers to preventive care, detection, and treatment of fistula in in Nigeria and Uganda, with fundamental questions:

1. Does implementation of this comprehensive intervention increase fistula care seeking, diagnosis, and surgical repairs?

2. Can digital health interventions and transportation vouchers reduce barriers to seeking as well as receiving fistula care?

3. Do focused training and job aids increase PHC provider abilities to diagnose and refer?

4. How do community outreach agents and providers interact to promote an efficient, community-based referral system?

\section{Methodology}

Figure 1 (on the following page) illustrates a conceptual model for IR to assess a complex social and behavior change (SBC) intervention to enhance access to fistula treatment. The model, from left to right, charts actions and resources contributing to short- and long term outcomes. Key intervention features include specific resources as well as strategic and multi-sectoral stakeholder partnerships-a digital health mechanism, PHC providers, community outreach agents, transportation providers, and fistula care center staff-all using a screening and referral mechanism. Specific intervention activities and tools include the fistula screening hotline as well as communication and advertising materials, training and job aids for implementing partners, a transportation voucher mechanism, and monitoring tools to track progress by all involved partners. 
Figure 1. Conceptual model

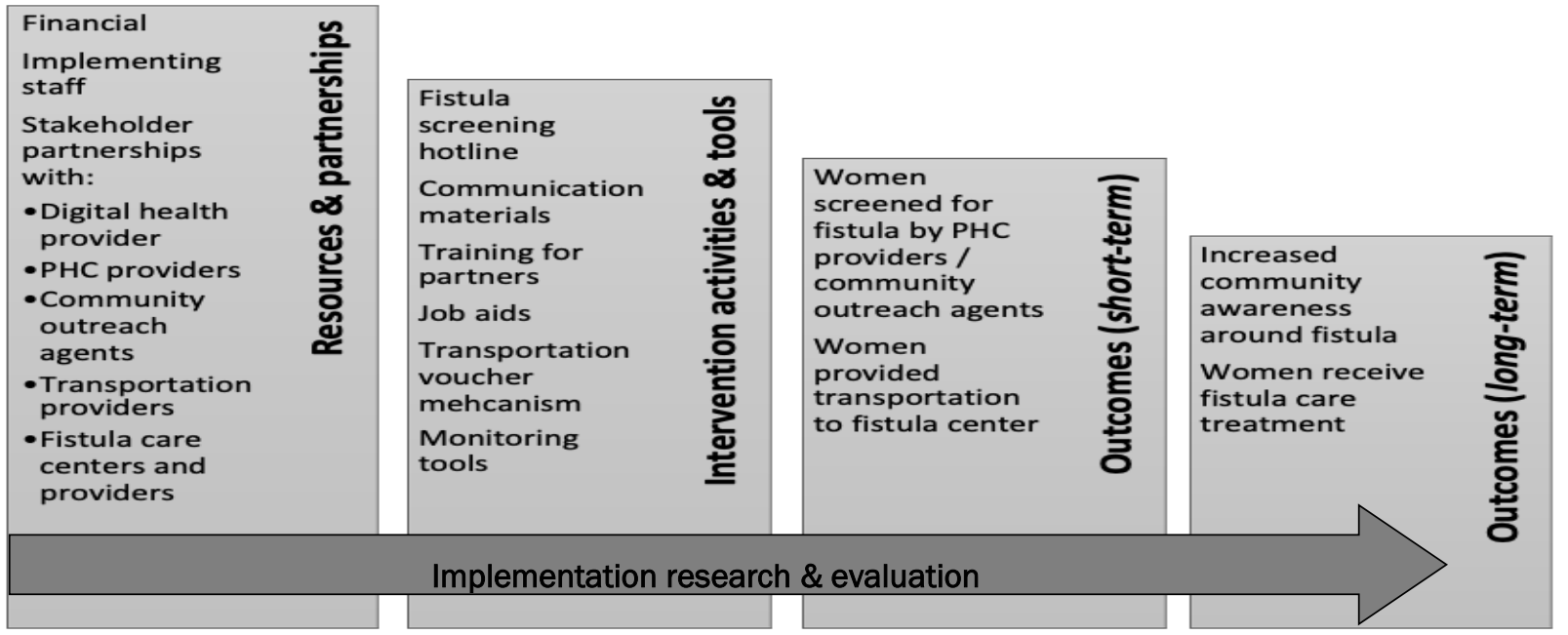

Short term goals for intervention outcomes were women screened for fistula by PHC providers and community outreach agents, with positively screened women's free transportation to a fistula center, with these interim outcomes contributing to the longer term outcomes of increased community awareness of fistula and women's treatment. IR and learning through the intervention leads to the evaluated outcomes.

\section{Study Setting}

This IR study took place in Ebonyi state in southeast Nigeria, Katsina state in northern Nigeria, and Uganda's Central 1 sub-Region. Sites were determined from formative research findings, including fistula repair center capacities, along with discussions with implementers, donors, and stakeholders. Local Government Area (LGA, in Nigeria) and district (in Uganda) intervention and comparison areas were selected in collaboration with FC+ and fistula repair facilities. Sites with high caseloads documented by referral hospitals were prioritized as proxies for heavy burden areas. In Nigeria, sites with limited deferred cases for treatment were selected, given anticipated potential increases in cases due to the intervention.

Ebonyi, Nigeria: The National Fistula Center (NOFIC) at Abakaliki in Ebonyi conducted 283 surgical fistula repairs with support from FC+ from October 2014 through September 2015. NOFIC Ebonyi is properly functioning, provides surgical fistula repair routinely, and treats women with fistula in a timely manner, with no deferred cases. Ikwo LGA was selected as the intervention area and Izzi LGA as the comparison area in Ebonyi, which has an estimated population of 2.2 million, with 13 LGAs.

Katsina, Nigeria: NOFIC at Babbar Ruga in Katsina conducted 309 surgical fistula repairs with support from FC+ during the same period. NOFIC Katsina provides surgical fistula repair routinely and is able to treat fistula in a timely manner. Katsina LGA was selected as the intervention area and Batsari LGA as the comparison area in Katsina state, which has an estimated population of 5.8 million in 34 LGAs.

Central 1 sub-Region, Uganda: The Fistula Center at Kitovu Mission Hospital in Masaka district, Central 1 region conducted 200 surgical fistula repairs with support from $\mathrm{FC}+$ during the same period. Kitovu, the leading fistula treatment site in Uganda, performed more than 50 percent of the 3,846 reported surgical fistula repairs in Uganda in the past 11 years. Kalungu district was selected as the intervention area and Masaka district as the comparison for Uganda's Central region, with an estimated 9.5 million population. 
Following the baseline assessment, FC+ designed and implemented a multi-pronged intervention employing a fistula screening hotline, transportation voucher, and mass media tools. PHC providers and community outreach agents received refresher training after midline data collection.

An endline evaluation followed the intervention.

\section{Intervention Components}

The intervention followed a "3-1-1" model with three communication mechanisms for fistula messaging, one screening algorithm for PHC and community detection, and one transportation voucher to enable hospital access for diagnosis and repair. The intervention used a standard fistula screening algorithm for both communication and referral contexts: communities, PHC facilities, mass media, and the hotline. The transportation voucher enabled positively screened women to travel for free, to and from an accredited fistula treatment facility. FC+ country teams implemented the intervention in two sites in Nigeria and one site in Uganda. Population Council IR evaluated the effects of this intervention.

\section{Three Communication Mechanisms}

Mass media and fistula screening hotline: FC+ partnered with Viamo (formerly Voto Mobile) to develop a free mobile hotline to screen women for fistula with IVR technology. The hotline was available in English, Igbo, Hausa, and Pidgin in Nigeria, and in Luganda in Uganda. Contextualized communication materials advertising the hotline were developed and disseminated through radio, community events, posters, and flyers at health facilities. Community outreach agents contacted women within intervention LGAs and district who screened positively via the hotline. Women who lived outside the catchment area who screened positively received a short message service (SMS) text with referral information to their closest fistula facility.

Community outreach agents: $\mathrm{FC}+$ trained community volunteers from the community-based organizations (CBOs) DOVENET and FOMWAN in Nigeria and Ministry of Health (MoH) Village Health Team (VHT) members in Uganda to fulfill multiple roles in strengthening fistula screening and referral systems within their communities. Throughout the intervention, trained volunteers conducted community outreach activities and shared information about the importance of birth preparedness and skilled delivery, risks of $\mathrm{P} / \mathrm{OL}$ and obstetric fistula, and available fistula treatment services. They advertised the fistula screening hotline to their communities, and often utilized it, along with a job aid, to identify women with incontinence and facilitate their free transportation to a treatment facility via the voucher mechanism.

PHC providers: For strengthening fistula screening and PHC referrals, FC+ trained health care providers (doctors, midwives, nurses, community health care workers) from intervention PHC clinics. Throughout the intervention, trained PHC providers advertised the fistula screening hotline to their patients, screened women with incontinence for fistula at their clinics using a job aid, and facilitated free transportation to a treatment facility through the voucher mechanism.

\section{One Screening Algorithm for Fistula Detection}

Community outreach agents and PHC providers used a job aid and, if helpful, the screening hotline, both of which used one simple screening question to identify genital fistula signs and symptoms and provide guidance on referral-Key screening question: Do you currently experience constant leakage of urine or feces from your vagina day and night, even when you are not urinating or trying to urinate?

\section{One Enabler}

The intervention provided a transportation voucher for suspected fistula cases and a companion for travel to the fistula repair center. FC+ partnered with local transportation providers in each intervention catchment area, and community outreach agents and PHC providers linked positively screened women with a local driver to transport them to and from the fistula facility for free. 
FC+ began intervention planning and coordination in July 2016, concurrent with Population Council baseline data collection. With guidance and support from the FC+ global team, FC+ country staff identified and established agreements with key external stakeholders-fistula treatment providers, PHC providers, community outreach agents, and transportation providers-for the intervention, and developed a training curriculum, monitoring tools, and communications materials. FC+ and Viamo collaborated in designing and pilot testing the fistula screening hotline using IVR.

Figure 2. IR timeline

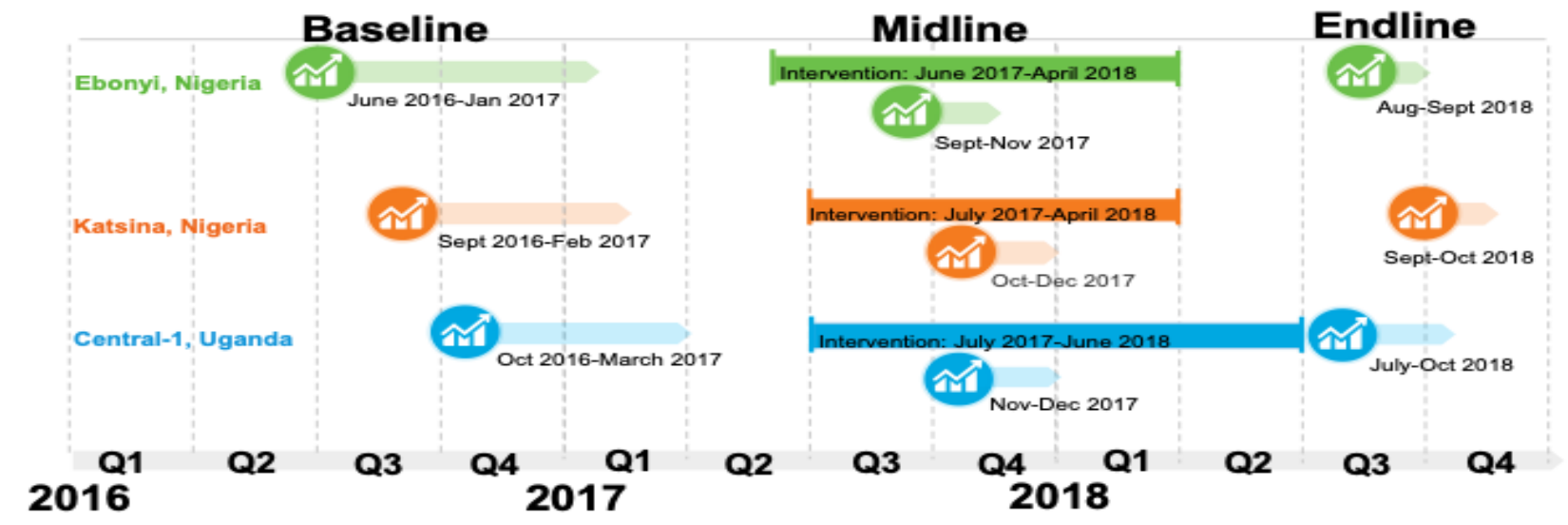

In the first and second quarters (Q1 and Q2) of 2017, FC+ implemented training of PHC providers and community outreach agents in the intervention LGAs in Nigeria and Uganda district. The three day PHC provider training focused on basic emergency obstetric care, screening for genital fistula, and how to refer positively screened women for treatment through the intervention's transportation voucher mechanism. In Nigeria, the training included 94 PHC providers (48 in Ebonyi, 46 in Katsina), and in Uganda 42 PHC providers were trained.

The two day community outreach agent training focused on knowledge, skills, and tools to promote healthy practices before, during, and after childbirth, as well as how to identify potential fistula cases, using either a paper-based job aid or the fistula screening hotline, and referring women for diagnosis and treatment via the intervention's transportation voucher mechanism. In Nigeria, participants included community volunteers from the CBOs DOVENET in Ebonyi and FOMWAN in Katsina, and in Uganda participants were MoH VHT members. Eighty-two CBO volunteers (46 in Ebonyi, 36 in Katsina) and 275 VHT members were trained, with differences in numbers of trained community outreach agents due to varying operations of existing community outreach structures: In Uganda, VHTs operate in each village, while in Nigeria CBO volunteers oversee larger administrative areas, resulting in a greater density of trained community outreach agents in Uganda.

The scope and reach of the intervention differed in each country: In Uganda, FC+-supported VHTs were only responsible for the intervention district, while in Nigeria FC+ worked with $\mathrm{CBO}$ s on fistula outreach throughout the states of Ebonyi and Katsina as part of a broader project activity. Radio messages in Nigeria advertising the hotline aired throughout both states, with $\mathrm{FC}+$-supported volunteer outreach activities and free transportation to fistula repair centers implemented throughout the states; however, while free transportation was offered statewide, the voucher mechanism was only utilized within the intervention LGAs.

Midline evaluation findings informed refresher training and supportive supervision visits by FC+ country teams to improve partners' comprehension of job aids and information, education and communication (IEC) materials, the fistula screening hotline, the voucher mechanism, and monitoring tools, as well as strengthening relationships between community outreach agents, PHC providers, fistula repair center staff, and drivers. 
In 2018 Q1, one day refresher trainings were provided for 128 intervention partners (PHC providers, community outreach agents, fistula providers, drivers) at each intervention site (72 in Ebonyi, 56 in Katsina) in Nigeria, and in Uganda FC+ conducted supportive supervision visits to 23 PHC providers and 216 VHTs.

\section{Methods and Data Sources}

A mixed methods approach answered the evaluation questions, employing a range of primary and secondary qualitative and quantitative data sources.

Figure 3. Evaluation questions and related data sources
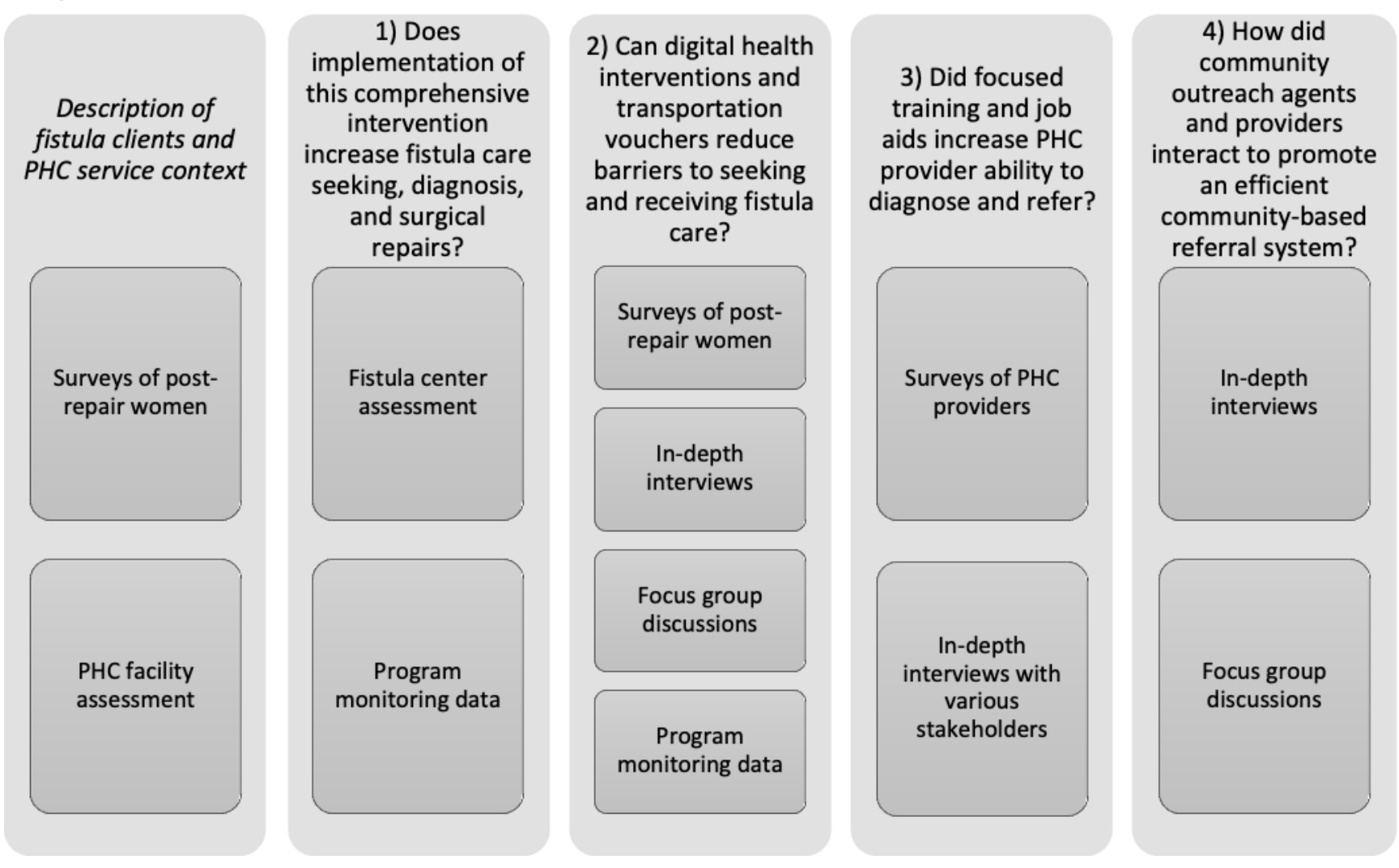

The detailed purpose, sampling, and sample sizes by methods measuring intervention outputs, as well as implementation outcomes and processes, are shown in Table 1. Baseline data were collected in all three sites shortly before the intervention; midline assessments were conducted between the third and sixth months of intervention implementation; and endline data were collected in each site after implementation was complete. Triangulated, the methods describe the effectiveness and nature of three intervention channels and components, and address the evaluation questions. 


\section{Intervention outputs-i.e. program data:}

Monitoring data for the intervention were collected in several ways:

- Call logs from the hotline were available through an online portal provided by Viamo and exported to a Microsoft Excel spreadsheet. FC+ country teams regularly checked the portal, exported the call logs, recorded calls on an electronic monitoring tool, and shared the information with community outreach agent coordinators for follow up.

- Intervention partners-community outreach agents, PHC providers, fistula repair center staff, transportation providers-each received a registrar notebook to record women screened, referred, and transported using the free voucher mechanism.

- Fistula facility record reviews of patients referred through the intervention recorded their diagnostic and treatment outcomes.

Quantitative summaries of hotline use and referral outputs were produced for the three intervention areas.

Intervention outcomes-including fistula repair referrals, provider knowledge and practice, women's fistula status, barriers, and enablers to care access, and community awareness of fistula causes and care options:

Quantitative data collection included facility assessments documenting fistula admissions and surgeries at the fistula center, as well as PHC facility capacities and resources in both comparison and intervention sites. The same PHC facilities were sampled at baseline and endline, with some attrition. Surveys of PHC providers, including nurses, midwives, and community health extension workers, explored their knowledge and practices of fistula recognition, care, and referral. While some PHC providers were the same at baseline and endline, they were not exactly matched due to general attrition and shifts during the implementation period. Post-repair fistula clients completed surveys exploring their fistula histories and experiences of barriers and enablers to seeking and receiving care. Descriptive summaries developed using Stata.12 software were provided for all quantitative data.

Implementation process experience from multiple perspectives-including challenges, successes, and sustainability implications for screening and referral at community and PHC levels using the hotline, job aids, and the transportation voucher:

Qualitative data collection explored stakeholders' experiences of the implementation process, including ways in which the intervention was modified during implementation to respond to contextual factors. Qualitative data collection also examined fistula client and community perspectives of barriers as well as enablers to fistula care, and normative attitudes about fistula causes and consequences.

Qualitative data were analyzed by a team that jointly developed a codebook of emergent themes from indepth readings of transcripts. Researchers used NVivo 11 software to organize and code transcripts, which generated charts and narrative summaries. This report provides narrative summaries and quotations from interviews related to implementation and experiences of the intervention components.

Data collection activities in Ikwo and Katsina (i.e. intervention) and Izzi and Batsari (i.e. comparison) LGAs in Nigeria, Kalungu (i.e. intervention) and Masaka (i.e. comparison) districts in Uganda at baseline, midline, and endline are provided in Table 1 (next page). 

Table 1: Data Collection Activities across 3 sites in Nigeria and Uganda

\begin{tabular}{|c|c|c|c|c|c|c|c|c|c|c|c|}
\hline \multirow{3}{*}{ Method } & \multirow{3}{*}{ Purpose } & \multirow{3}{*}{$\begin{array}{l}\text { Sampling } \\
\text { strategy }\end{array}$} & \multicolumn{3}{|c|}{ Baseline } & \multicolumn{3}{|c|}{ Midline } & \multicolumn{3}{|c|}{ Endline } \\
\hline & & & \multicolumn{2}{|c|}{ Nigeria } & \multirow{2}{*}{$\begin{array}{l}\text { Uganda } \\
\text { C1* }\end{array}$} & \multicolumn{2}{|c|}{ Nigeria } & \multirow{2}{*}{$\begin{array}{c}\text { Uganda } \\
\text { C1 }\end{array}$} & \multicolumn{2}{|c|}{ Nigeria } & \multirow{2}{*}{$\begin{array}{c}\text { Uganda } \\
\text { C1 }\end{array}$} \\
\hline & & & $\mathrm{EB}^{*}$ & $\mathrm{KT}^{*}$ & & EB & KT & & EB & KT & \\
\hline Facility assessments of PHCs & $\begin{array}{l}\text { Assessed health systems capacity and } \\
\text { contextualize the intervention setting }\end{array}$ & $\begin{array}{l}\text { Census-based per } \\
\text { LGA/district (same at } \\
\text { baseline and endline) }\end{array}$ & 39 & 37 & 50 & N/A & N/A & N/A & 38 & 31 & 43 \\
\hline Fistula center assessment & Tracked referrals and surgeries & $\begin{array}{l}\text { One FC+ supported } \\
\text { center per site }\end{array}$ & 1 & 1 & 1 & N/A & N/A & N/A & 1 & 1 & 1 \\
\hline Surveys of PHC providers & $\begin{array}{l}\text { Assessed knowledge, attitudes, and } \\
\text { operational challenges around } \\
\text { intervention implementation }\end{array}$ & $\begin{array}{l}\text { Sampled 1-3 per facility - } \\
\text { baseline and endline } \\
\text { respondents overlapping, } \\
\text { but not the same due to } \\
\text { attrition/ turnover }\end{array}$ & 117 & 88 & 119 & N/A & N/A & N/A & 100 & 93 & 100 \\
\hline $\begin{array}{l}\text { Surveys of post-repair } \\
\text { women }\end{array}$ & $\begin{array}{l}\text { Explored fistula history and the barriers } \\
\text { and enablers they experienced }\end{array}$ & $\begin{array}{l}\text { Convenient at during } \\
\text { recovery at fistula center }\end{array}$ & 91 & 81 & 96 & N/A & N/A & N/A & 51 & 44 & 47 \\
\hline $\begin{array}{l}\text { In-depth interviews: } \\
\text { - Post-repair clients* } \\
\text { - Community volunteers } \\
\text { - Community supervisors } \\
\text { - PHC providers } \\
\text { - Fistula center staff } \\
\text { - District managers } \\
\text { - FC+ staff }\end{array}$ & $\begin{array}{l}\text { Content validate barrier index among } \\
\text { women who lived with fistula at } \\
\text { baseline, and } \\
\text { To understand the implementation } \\
\text { process from implementers and } \\
\text { stakeholders at midline and endline }\end{array}$ & $\begin{array}{l}\text { Purposive, based on role } \\
\text { in intervention }\end{array}$ & 30 & 30 & 29 & 19 & 18 & 18 & 11 & 19 & 18 \\
\hline $\begin{array}{l}\text { Focus group discussions with } \\
\text { men and women residing in } \\
\text { selected communities }\end{array}$ & $\begin{array}{l}\text { Explored barriers and enablers to } \\
\text { accessing care and normative attitudes } \\
\text { toward fistula causes and } \\
\text { consequences }\end{array}$ & $\begin{array}{l}\text { Purposive to capture } \\
\text { community norms }\end{array}$ & 0 & 4 & 6 & N/A & N/A & N/A & 8 & 8 & 8 \\
\hline Program monitoring data & $\begin{array}{l}\text { Assessed number of hotline callers, } \\
\text { referrals, transport vouchers, fistula } \\
\text { center trips, community-based follow } \\
\text { up }\end{array}$ & N/A & & $\mathrm{N} / \mathrm{A}$ & & & $\begin{array}{r}\text { ventio } \\
\text { onl }\end{array}$ & period & & & \\
\hline
\end{tabular}

*EB: Ebonyi, KT: Katsina, C1: Central 1 sub-Region 


\section{Findings}

\section{Fistula Clients}

In Nigeria, nearly two thirds (68\%) of women treated in Katsina were from rural areas in the state, whereas in Ebonyi nearly two thirds (65\%) of women treated were from other states. In Uganda, nearly all $(92 \%)$ women treated were from the Central 1 sub-region. Women interviewed in Ebonyi were slightly older (59\% were 26 to 45 years of age) than women in either Katsina or Uganda (where approximately $65 \%$ were ages 15 to 35). Table 2 presents the socio-demographic characteristics of fistula clients at the repair centers at baseline (see Table A1 in appendix for endline).

Education varied by site. In Ebonyi, most women had secondary (59\%) or primary (28\%) education, while in Katsina most women had either no education (37\%) or Quranic only (47\%). In Uganda, most women had either primary (65\%) or secondary (21\%) education. At baseline, over half of women interviewed reported current employment in addition to 'normal' housework in Ebonyi (57\%) and Uganda (58\%), while in Katsina, most women did not perform extra work (84\%). Tables A2 and A3 in the appendix provide descriptive summaries of the financial capacities, economic autonomy, and marital statuses of postrepair fistula clients surveyed in all three sites.

Women interviewed represented the dominant religious and ethnic groups from their areas. Most women in Ebonyi (96\%) and in Uganda (89\%) were Christian, while in Katsina all were Muslim (100\%). In Ebonyi most women were Igbo (81\%), in Katsina they were Hausa (65\%), and in Uganda they were Baganda (45\%), Bakiga (24\%), or Banyoro (21\%). In Nigeria, most women were married (73\% in Ebonyi, $86 \%$ in Katsina), while in Uganda, 56 percent were married or cohabiting, while 29 percent were widowed. In Katsina, approximately half of women reported additional wives (52\%) of their husbands, with lower proportions in Ebonyi (20\%) and in Uganda (22\%). A majority of post-repair clients were married between 11 and 20 years of age in Katsina (98\%) and in Uganda (78\%); whereas in Ebonyi, most were married between ages 11 and 20 (21\%) or 21 and $30(46 \%)$.

Post-repair client surveys explored women's reproductive health $(\mathrm{RH})$ and fistula histories, along with the barriers and enablers to their fistula care (Table A4 in appendix). Most women had first sexual intercourse between the ages of 15 and 19 in Katsina (78\%) and in Uganda (87\%), whereas in Ebonyi most were between either ages 15 and 19 (51\%) or 20 and 24 (32\%). Similarly, while age at first pregnancy was lower (between 15 and 19) in Katsina (90\%) and in Uganda (70\%), it was higher (20 and older) in Ebonyi (74\%). In Nigeria, most women had either no (29\% in Ebonyi, $14 \%$ in Katsina) or one child (26\% in Ebonyi, $15 \%$ in Katsina), whereas in Uganda women had either one child (44\%) or five or more (18\%).

Women in Uganda demonstrated positive pregnancy and delivery practices, including preventative fistula behaviors, with the vast majority having antenatal care (ANC) during their last full term pregnancy (97\%). Fewer women reported ANC during their last pregnancy in Ebonyi (81\%) and in Katsina (56\%). In Uganda, the highest proportion of women delivered in a hospital or PHC (89\%), followed by Katsina (86\%) and Ebonyi (80\%). In all three sites, between 78 percent and 94 percent of women reported complications during their last delivery, with prolonged labor and bleeding described most frequently.

Post-repair clients' fistula histories recorded at baseline (Table 3; Table A5 in appendix shows endline) revealed that the length of time a woman lived with fistula varied by site, and while most women had lived with fistula less than two years-in Katsina less than one year (59\%) or two years (27\%), in Ebonyi less than a year (50\%) or under two years (23\%), and in Uganda less than a year (42\%) or two years (14\%)- 
substantial proportions of women who had lived with fistula for 10 years or more: eight percent in Ebonyi and 25 percent in Uganda. Nearly all women reported that their leaking started after live or stillborn delivery (85\% to 99\%), with deliveries either vaginal (32\% in Ebonyi, $41 \%$ in Katsina, $29 \%$ in Uganda), via cesarean section (62\% in Ebonyi, $25 \%$ in Katsina, 39\% in Uganda), or with forceps (7\% in Ebonyi, 35\% in Katsina, $18 \%$ in Uganda).

Over half of post-repair clients in Uganda had sought treatment previously (54\%), but in Nigeria over half of women had not sought treatment previously (73\% in Ebonyi and 52\% in Katsina). Among women who had sought treatment, significant numbers had contacted a health professional (24\% to $47 \%$ ). In Katsina and Uganda, greater percentages of post-repair clients treated previously had attempted fistula repair surgery (13\% and 14\%, respectively) than in Ebonyi (9\%).

Table 2. Socio-demographic characteristics of post-repair fistula clients at baseline

\begin{tabular}{|c|c|c|c|}
\hline & $\begin{array}{c}\text { Ebonyi, Nigeria } \\
n=91, \%\end{array}$ & $\begin{array}{c}\text { Katsina, Nigeria } \\
n=81, \%\end{array}$ & $\begin{array}{c}\text { Central-1, Uganda } \\
n=96, \%\end{array}$ \\
\hline \multicolumn{4}{|l|}{ Residence } \\
\hline City or town & 4.4 & 9.9 & 6.2 \\
\hline Rural area & 30.8 & 67.9 & 91.7 \\
\hline Outside Ebonyi, Katsina, Central 1 & 64.8 & 22.2 & 2.1 \\
\hline \multicolumn{4}{|l|}{ Age } \\
\hline $15-25$ years & 17.6 & 49.4 & 34.4 \\
\hline 26-35 years & 34.1 & 14.8 & 33.3 \\
\hline $36-45$ years & 25.3 & 0.0 & 21.9 \\
\hline 46 and above & 6.6 & 0.0 & 6.3 \\
\hline Missing & 16.5 & 35.8 & 4.2 \\
\hline \multicolumn{4}{|l|}{ Education } \\
\hline None & 12.1 & 37.0 & 13.5 \\
\hline Primary school & 27.5 & 13.6 & 64.6 \\
\hline Secondary school and more & 60.4 & 2.5 & 21.9 \\
\hline Quranic only & 0.0 & 46.9 & 0.0 \\
\hline \multicolumn{4}{|l|}{ Religion } \\
\hline Christian & 95.6 & 0.0 & 88.5 \\
\hline Muslim & 3.3 & 100.0 & 11.5 \\
\hline No Religion & 1.1 & 0.0 & 0.0 \\
\hline \multicolumn{4}{|l|}{ Ethnicity } \\
\hline Baganda & N/A & N/A & 44.8 \\
\hline Bakiga & N/A & N/A & 6.3 \\
\hline Banyoro & N/A & N/A & 2.1 \\
\hline Banyankole & N/A & N/A & 20.8 \\
\hline Basoga & N/A & N/A & 2.1 \\
\hline Hausa & 1.1 & 65.4 & N/A \\
\hline Igbo & 81.3 & 0.0 & N/A \\
\hline Fulani & 0.0 & 28.4 & N/A \\
\hline Ibibio & 2.2 & 0.0 & N/A \\
\hline Kanuri & 0.0 & 3.7 & N/A \\
\hline Other & 13.2 & 2.5 & 24.0 \\
\hline
\end{tabular}


Table 3. Fistula history of post-repair fistula clients at baseline, by site

\begin{tabular}{|c|c|c|c|}
\hline & $\begin{array}{c}\text { Ebonyi, Nigeria } \\
n=91, \%\end{array}$ & $\begin{array}{c}\text { Katsina, Nigeria } \\
n=81, \%\end{array}$ & $\begin{array}{c}\text { Central 1, Uganda } \\
n=96, \%\end{array}$ \\
\hline \multicolumn{4}{|l|}{ Length of time living with fistula } \\
\hline Less than a year & 49.5 & 59.3 & 41.7 \\
\hline $1-2$ years & 23.1 & 27.2 & 13.5 \\
\hline $3-4$ years & 8.8 & 4.9 & 6.3 \\
\hline $15-10$ years & 11.0 & 4.9 & 12.5 \\
\hline $10+$ years & 7.7 & 3.7 & 25.0 \\
\hline \multicolumn{4}{|l|}{ Problem of leaking started } \\
\hline After delivering a live or stillborn baby & 84.6 & 98.8 & 87.5 \\
\hline After abdominal or pelvic surgery & 8.8 & 0.0 & 9.4 \\
\hline After a sexual assault or other injury & 1.1 & 1.2 & 0.0 \\
\hline From birth & 0.0 & 0.0 & 3.1 \\
\hline None of the above & 5.5 & 0.0 & 0.0 \\
\hline Don't know & 0.0 & 0.0 & 0.0 \\
\hline \multicolumn{4}{|l|}{ Delivery after leaking started was } \\
\hline Normal delivery & 31.9 & 40.7 & 29.2 \\
\hline Assisted vaginal delivery & 6.6 & 34.6 & 17.7 \\
\hline Cesarean section & 61.5 & 24.7 & 38.5 \\
\hline Abdominal surgery (ruptured uterus) & 0.0 & 0.0 & 2.1 \\
\hline Missing & 0.0 & 0.0 & 12.5 \\
\hline \multicolumn{4}{|l|}{ Ever sought treatment for leaking previously } \\
\hline Yes & 27.5 & 48.1 & 54.2 \\
\hline No & 72.5 & 51.9 & 45.8 \\
\hline \multicolumn{4}{|l|}{ Previously sought treatment from: } \\
\hline Health professional & 25.3 & 23.5 & 46.9 \\
\hline Community or village health worker & 1.1 & 0.0 & 0.0 \\
\hline Traditional or spiritual healer or other provider & 0.0 & 22.2 & 7.3 \\
\hline Other & 1.1 & 1.2 & 0.0 \\
\hline Not applicable & 72.5 & 51.9 & 45.8 \\
\hline \multicolumn{4}{|l|}{ Previous treatment involved surgery } \\
\hline Yes & 8.8 & 13.6 & 12.5 \\
\hline No & 17.6 & 34.6 & 41.7 \\
\hline Not applicable & 72.5 & 51.9 & 45.8 \\
\hline \multicolumn{4}{|l|}{ Number of times sought previously treatment } \\
\hline 1 & 14.3 & 11.1 & 17.7 \\
\hline 2 & 6.6 & 18.5 & 11.5 \\
\hline 3 & 1.1 & 8.6 & 8.3 \\
\hline 4 & 2.2 & 1.2 & 5.2 \\
\hline 5 or more & 0.0 & 4.9 & 11.5 \\
\hline Not applicable & 72.5 & 51.9 & 45.8 \\
\hline Missing & 3.3 & 3.7 & 0.0 \\
\hline
\end{tabular}


Fisher's exact tests examined the relationship between length of time living with fistula and three key demographics and found all three variables significantly related to fistula duration: age $(p<.001)$, education $(p<.001)$, marital status $(p<.001)$. Table 4 presents a cross-tabulation of the percentage of post-repair clients living with fistula for varied durations, with their age, education, and marital status.

Table 4. Length of time post-repair clients lived with fistula by key demographics across all sites

\begin{tabular}{lccc}
\hline & \multicolumn{3}{c}{ Percentage of women living with fistula $(\mathrm{n}=410)$ for: } \\
& $<1$ year & 1-2 years & 3+ years \\
\hline Age & & & \\
\hline $15-25$ years & 19 & 7 & 6 \\
26 - 35 years & 17 & 6 & 10 \\
36 and above & 6 & 3 & 12 \\
\hline Education & & 7 & 8 \\
\hline None or Qur'anic only & 21 & 7 & 17 \\
Primary school & 15 & 6 & 6 \\
Secondary and more & 13 & & \\
\hline Marital status & & 6 & 11 \\
\hline Single, separated, divorced, widowed & 9 & 14 & 19 \\
Married or cohabitating & 41 & & \\
\hline
\end{tabular}

\section{Primary Health Care Services}

The majority of participating PHC facilities are public: in Nigeria 92 percent and 68 percent in Uganda. In Uganda and in Katsina the remaining facilities are private, while in Ebonyi they are faith-based. Uganda's PHCs had better functioning capacities than those in Nigeria, while Nigeria's PHCs in Katsina functioned at somewhat a higher capacity than those in Ebonyi.

Table 5. PHC facility characteristics at baseline

\begin{tabular}{lccc}
\hline & $\begin{array}{c}\text { Intervention LGA } \\
\text { in Ebonyi, Nigeria }\end{array}$ & $\begin{array}{c}\text { Intervention LGA } \\
\text { in Katsina, Nigeria }\end{array}$ & $\begin{array}{c}\text { Intervention District } \\
\text { in Central-1, Uganda }\end{array}$ \\
\hline & $\mathrm{n}=39, \%$ & $\mathrm{n}=37, \%$ & $\mathrm{n}=50, \%$ \\
\hline Ownership & & & \\
\hline Public & 92.3 & 91.9 & 68.0 \\
Private & 7.7 & 8.1 & 32.0 \\
\hline Facility capacity - has functional: & & & \\
\hline Private delivery room & 82.1 & 62.2 & 48.0 \\
Theater equipment & 12.8 & 21.6 & 10.0 \\
Infection prevention supplies & 43.6 & 59.5 & 72.0 \\
Running water & 66.7 & 27.0 & 62.0 \\
Refrigerator & 59.0 & 48.6 & 66.0 \\
Toilet & 51.3 & 67.6 & 96.0 \\
Electricity & 28.2 & 70.3 & 62.0 \\
Generator & 46.2 & 43.2 & 18.0 \\
Experiences power outages & 64.1 & 51.4 & 40.0 \\
\hline
\end{tabular}


While 70 percent of PHCs in Katsina and 62 percent in Uganda had functioning electricity, only 28 percent in Ebonyi did. Only 40 percent of PHCs in Uganda experienced power outages, compared to 51 percent in Katsina and 64 percent in Ebonyi. Nearly all PHCs in Uganda (96\%) had a functioning toilet, while only 68 percent in Katsina and 51 percent in Ebonyi did. Less than one third of PHC centers in all three sites had functioning theatre equipment, yet more than half of PHC centers in Uganda and Katsina had supplies and commodities for infection prevention, while in Ebonyi only 44 percent did. Despite the overall trend of PHCs in Uganda and Katsina functioning at higher capacities, a greater proportion of PHCs in Ebonyi, than in either Katsina or Uganda, had a private delivery room.

\section{Implementation of a comprehensive intervention affects fistula care-seeking, diagnosis, and surgical repairs}

In all three sites, service figures reveal overall increases in volume of admissions and surgeries during the intervention period, but with variations according to intervention activity. Peak quarters for greatest volume of admissions and surgeries were Q3 2017 in Ebonyi (107 admissions, 61 surgeries), Q1 2018 in Katsina (135 admissions, 135 surgeries), and Q1 2016 in Uganda (70 admissions, 62 surgeries). In Ebonyi there was a surge of activity (e.g. number of hotline calls and referrals through the intervention) within the first quarter of intervention implementation, followed by a decline after midline data collection (Figure 4). In Katsina, activity was initially more consistent and then reduced after midline (Figure 5). In Uganda, intervention activity fluctuated throughout the entire intervention, likely attributable to the Uganda treatment center's pooled effort model (Figure 6), through which women diagnosed are requested to return on a common date when a large number of repairs can be conducted by highly skilled providers, making it less easy to link timing of increased treatment to the intervention launch.

Figure 4. Fistula repair center admissions, surgeries and intervention outcomes in Ebonyi, Nigeria

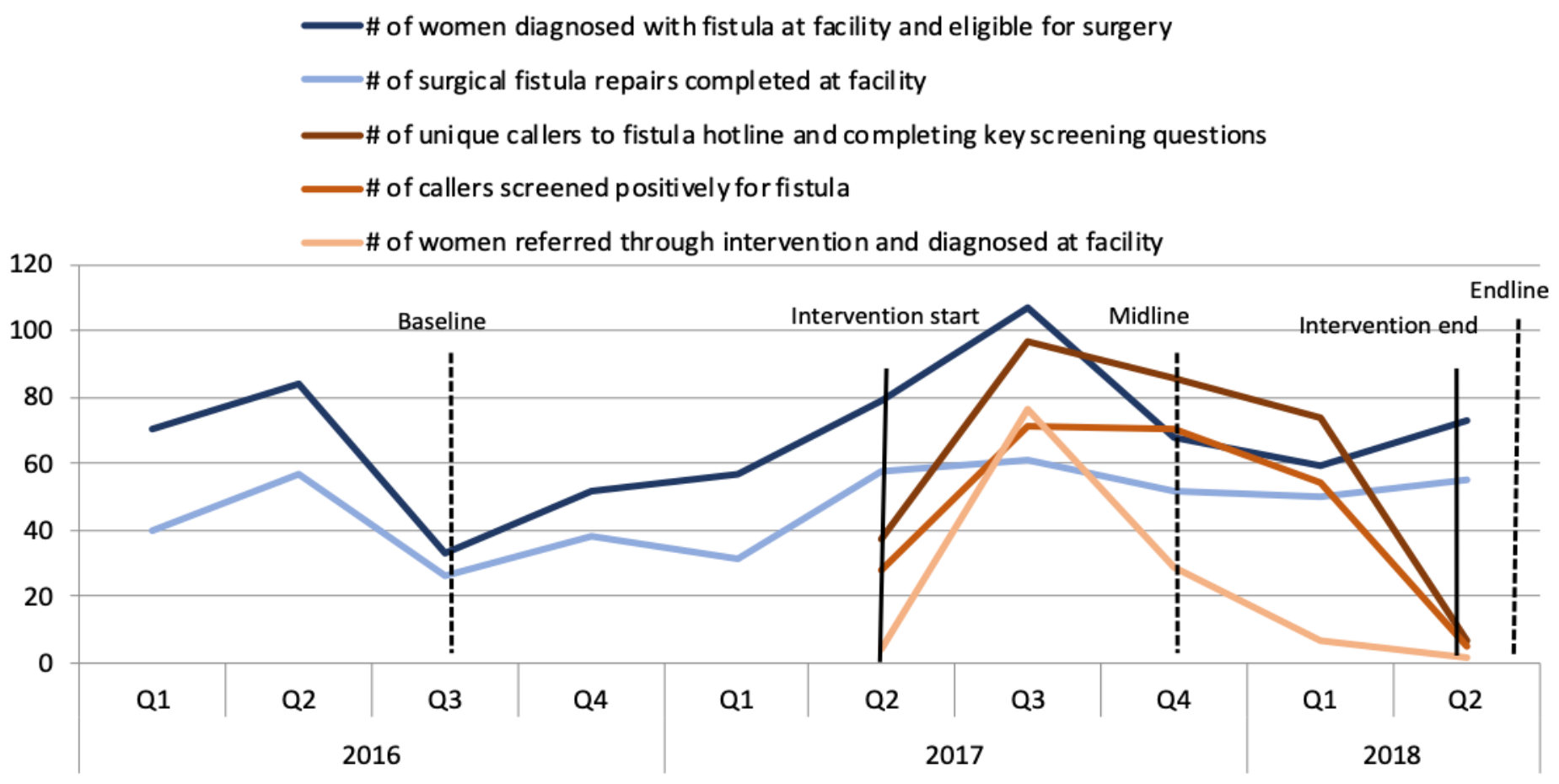



\# of women diagnosed with fistula at facility and eligible for surgery
\# of surgical fistula repairs completed at facility
\# of unique cal lers to fistula hot line and completing key screening questions
\# of callers screened positively for fistula
\# of women referred through intervention and diagnosed at facility

Figure 5. Fistula repair center admissions, surgeries and intervention outcomes in Katsina, Nigeria

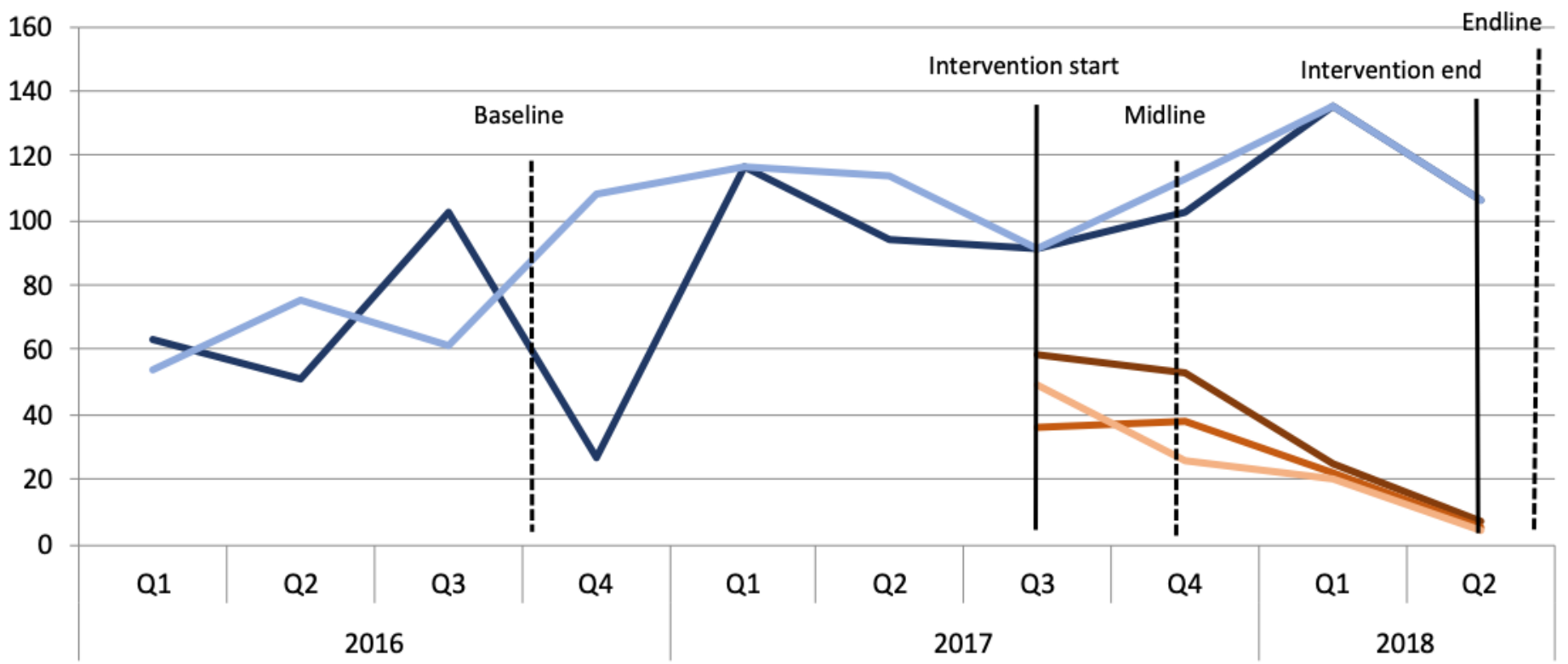

Figure 6. Fistula repair center admissions, surgeries and intervention outcomes in Central 1, Uganda

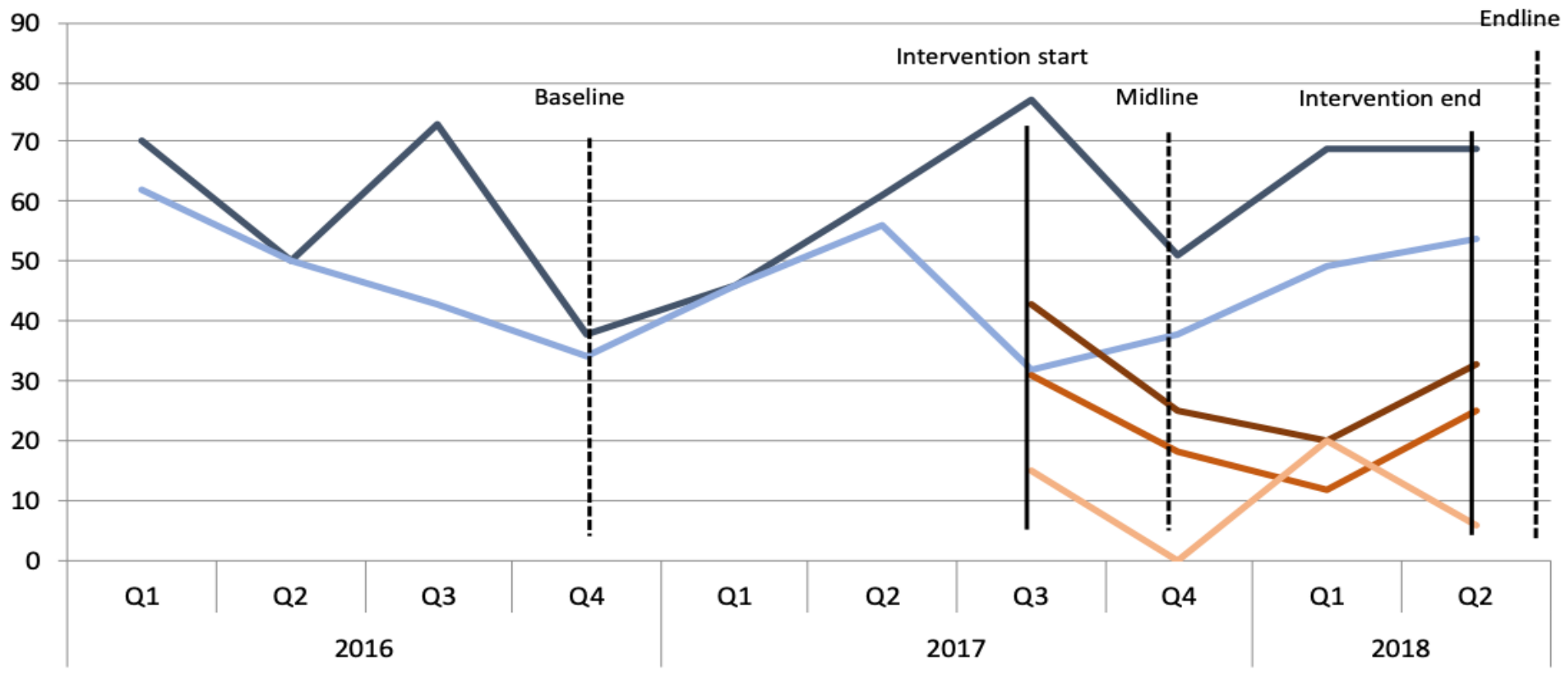


Notably, the number of women referred through the intervention (ref: program monitoring data) comprised a greater proportion of admissions and surgeries (ref: fistula center facility assessments) in Ebonyi (31\%) than in Katsina (23\%) and Kalungu in Uganda (15\%). During the intervention, the fistula facility in Ebonyi diagnosed and admitted 386 clients for surgery, 118 of whom were referred through the intervention, in Katsina the fistula facility admitted 435 women, 99 of whom were referred through the intervention, and in Uganda a total of 266 women were admitted, 41 referred through the intervention. The effectiveness of an intervention for fistula care use may be influenced by exposure time, broader health system considerations, and socio-cultural contexts.

\section{Digital health interventions and transportation vouchers reduce barriers to fistula care}

\section{Program monitoring data}

All three sites experienced high volumes of hotline calls, with a total of 1,205 and 594 unique callers to the hotline over 12 months in Nigeria and Uganda, respectively. About half of callers in Nigeria (47\%) and Uganda (54\%) completed both the key screening and residency questions, and of those callers, 69 percent in Nigeria and 64 percent in Uganda screened positively for fistula, with 76 percent of callers from Ebonyi, 70 percent in Katsina, and 69 percent from Kalungu in Uganda screening positively for fistula.

With 69 percent to 76 percent of callers screening positively for fistula, the screening tool is a promising SBC intervention that can be integrated with other strategies targeting this vulnerable group. The spillover effects of the advertising and word-of-mouth promotion of the hotline are evident from the fact that many callers phoned in from outside intervention catchment areas. Uganda's higher proportion is a result of the mass media hotline promotion restriction to the intervention district (i.e. Kalungu), compared to Nigeria where the mass media promotion was statewide (see Table A7 in appendix for disaggregation by quarter).

Table 6. Intervention outputs

\begin{tabular}{|c|c|c|c|c|c|c|}
\hline & \multirow[t]{2}{*}{$\begin{array}{l}\text { Means } \\
\text { of } \\
\text { verification }\end{array}$} & \multicolumn{3}{|c|}{$\begin{array}{l}\text { Nigeria } \\
\text { June } 2017 \text { - } \\
\text { April } 2018\end{array}$} & \multicolumn{2}{|c|}{$\begin{array}{l}\text { Uganda } \\
\text { July } 2017 \text { - } \\
\text { June } 2018\end{array}$} \\
\hline & & Ebonyi & Katsina & Total & Kalungu & Total \\
\hline $\begin{array}{l}\text { Number of unique fistula screening hotline } \\
\text { callers }\end{array}$ & Viamo & - & - & 1,205 & - & 594 \\
\hline $\begin{array}{l}\text { Number of callers completing key screening and } \\
\text { location question }\end{array}$ & Viamo & 301 & 144 & 572 & 121 & 321 \\
\hline Number of callers screened positively for fistula & Viamo & 228 & 101 & 394 & 86 & 205 \\
\hline $\begin{array}{l}\text { Number of women referred to fistula repair } \\
\text { center and utilized transport voucher mechanism } \\
\text { *Nigeria intervention LGAs only }\end{array}$ & $\begin{array}{l}\text { Partner } \\
\text { registrars }\end{array}$ & 17 & 3 & - & 27 & - \\
\hline $\begin{array}{l}\text { Number of women referred through intervention } \\
\text { and diagnosed (with fistula) at fistula repair } \\
\text { center }\end{array}$ & $\begin{array}{l}\text { Facility } \\
\text { records }\end{array}$ & $\begin{array}{l}118 \\
(54)\end{array}$ & $\begin{array}{l}99 \\
(52)\end{array}$ & - & $\begin{array}{c}41 \\
(22)\end{array}$ & - \\
\hline $\begin{array}{l}\text { Number of women referred through intervention } \\
\text { and received fistula treatment at fistula repair } \\
\text { center }\end{array}$ & $\begin{array}{l}\text { Facility } \\
\text { records }\end{array}$ & 35 & 39 & - & 19 & - \\
\hline
\end{tabular}


Transportation voucher use, limited in all sites, was greater in Ebonyi's intervention LGA, where all women $(n=17)$ referred through the intervention utilized it. In Katsina and Uganda, the number of women using the transportation voucher was particularly low compared to the total number of women who screened positively. In Nigeria, 17 women in Ebonyi and three in Katsina utilized the voucher, among 118 women in Ebonyi and 99 in Katsina referred through an intervention communication channel for diagnosis at a fistula repair center. In Uganda, 27 women from the intervention district utilized the free transportation voucher mechanism among 41 women referred for diagnosis. The proportion of women referred through the intervention and then diagnosed with fistula was comparable in each site: 46 percent in Ebonyi, 53 percent in Katsina, 54 percent in Uganda.

\section{Fistula screening hotline}

Most stakeholders (including FC+ staff, local Health managers, fistula clients, VHTs, PHC providers) reported at midline and endline that the fistula hotline is an effective innovation for screening and referring patients to PHCs and treatment facilities. They describe it as instrumental in providing fistularelated information to women, as well as allowing women to self-screen.

"With that hotline, you can press, and they give you directions properly and you don't lose track. It helps them [women] because it gives them directives...there is a health worker who responds to you and tells you to go to Kitovu like this and that."

VHT, midline, Uganda

Among women living with fistula, preferred information sources and perceived enablers to treatment include radio, hotlines, and community volunteer efforts.

"A VHT came and told me about flyers with some numbers which you call. I went, she gave me that number, and I called."

Hotline caller, midline, Uganda

While communication materials such as flyers promoting the hotline were distributed through VHTs in communities and at health facilities, gaps in coverage persist.

"This time [before accessing treatment at Kitovu Fistula center], they had made announcements over the radio. There is a VHT who came and told me, "[name] there are some flyers they have sent us which have some numbers which you can come and get and try to call them'...and I called them."

Patient who called the hotline by herself, midline, Uganda

Respondents also reported that the hotline reduced stigma by providing confidentiality for fistula screening, particularly when well-publicized and language-sensitive. The hotline's broad reach increased general awareness, self-screening through the hotline, community volunteer-assisted referrals, and transportation to the fistula center.

"Because of stigma, the person thinks, it's just me [a woman with fistula] and the radio gives the number-[she] calls the number...it was a wonderful strategy and really helped."

Health program manager, endline, Ebonyi, Nigeria

Challenges with the hotline included limited mobile phone ownership and poor cellular networks that affected operability by both women and community agents. Katsina was less affected, which has better cellular connectivity.

"The network in our villages is a problem, so one might call the hotline and the network fails which becomes a problem...one patient has been calling on it now days like for a week the number is not available."

Driver, intervention site, endline Uganda

"Many in our locality call the hotline...the network may be bad, we may not get what you need at the exact moment, but the hotline will be okay." Community volunteer, endline, Ebonyi, Nigeria 
Others critiqued the impersonal nature of automated hotline recordings.

"What is complicated...you only talk with a computer and that is it...I was about to lose hope. I wondered why we cannot get to people and instead the computer voices..."

Post-repair client who called hotline, endline, Uganda

Integrating a mobile screening service to help women learn about fistula and care options with a strengthened community-based referral mechanism for fistula appears to be a particularly user-friendly approach for stigmatized conditions, in addition to reaching large populations.

\section{Transportation voucher}

Fistula center staff, transportation officers, PHC providers, post-fistula repair clients, and other stakeholders expressed satisfaction with the transportation voucher and fistula center referral process.

"I was given a transport voucher which enabled a private car to come and carry me from a PHC...to a fistula center. After the operation, the same car came and carried me home after I submitted the last voucher to the hospital."

Post-repair client, endline, Ebonyi Nigeria

Challenges with voucher use were reported both at midline and endline, and included confusion about the processes of receipt and use, along with communication gaps between implementers. Transportation vouchers were not consistently offered to all patients' homes due to lack of infrastructural investment and seasonal challenges (e.g. rain).

"Patient was not taken right to her home because the distance she is remaining with would necessitate her to walk but it happens in situations whereby the vehicle cannot access her home due to heavy rains."

Transport officer, midline, Uganda

Respondents described gendered concerns about women traveling alone in some communities, creating significant hesitation among some to accept free transportation.

"It will not be easy for a community volunteer to go to somebody's house to take his wife even if [the repair] is free. We liaise with traditional rulers and leaders, and they go there for pick up to have peace of mind."

Program Manager, community-based organization, endline, Katsina Nigeria

\section{Barriers to care}

While the implementation experience was generally positive, its challenges manifest in remaining barriers to care. Post-repair clients at baseline $(n=268)$ and endline $(n=142)$ responded with agreement or disagreement to 43 illustrative statements used as proxies for the overall experience of fistula care barriers. (Table A8 in the appendix provides the comprehensive list of these illustrative statements.) These items captured awareness of fistula's causes, manifestations and care options, restrictive cultural beliefs, gender norms affecting women's care-seeking, psychological consequences, social stigma, financial costs, transportation and infrastructure, and health care quality and interactions. In all three sites, many women agreed with barrier statements both at baseline and endline.

Exploratory and confirmatory factor analyses led to composite measures demonstrating favorable psychometric properties such as good reliability and validity, and results from these analyses are described in detail in a forthcoming manuscript investigating composite measures for assessing barriers to care in Nigeria and Uganda. ${ }^{15}$ The final composite measures, including a financial and transportation inaccessibility index (score range 6 to 24) and a multi-dimensional barrier to fistula care index with three sub-scales including limited awareness (score range 4 to 16), social abandonment (score range 6 to 24), and internalized stigma (score range 7 to 28 ) are provided in Table 7 (next page). 
Table 7. Multi-dimensional barrier to fistula care, financial and transportation inaccessibility indices

\begin{tabular}{|c|c|c|}
\hline \multicolumn{3}{|c|}{ Barriers to Fistula Care Index } \\
\hline Sub-scale & Items $(n=17)$ & Response categories \\
\hline $\begin{array}{l}\text { Limited } \\
\text { awareness } \\
\text { (4-item) }\end{array}$ & $\begin{array}{l}\text { I did not know that fistula is a medical condition that can be } \\
\text { treated. } \\
\text { I believed that having fistula was a curse. } \\
\text { I believed that my fistula was caused by diabolic means. } \\
\text { I did not know where to go for fistula repair. }\end{array}$ & \multirow{3}{*}{$\begin{array}{l}\text { Strongly disagree } \\
\text { Disagree } \\
\text { Agree } \\
\text { Strongly agree }\end{array}$} \\
\hline $\begin{array}{l}\text { Social } \\
\text { abandonment } \\
\text { (6-item) }\end{array}$ & $\begin{array}{l}\text { People who knew I had fistula avoided me. } \\
\text { My husband/intimate partner treated me poorly initially. } \\
\text { My husband/intimate partner treated me poorly later on. } \\
\text { My husband/intimate partner abandoned me. } \\
\text { I did not have someone to care for me and help me manage } \\
\text { my condition at home. } \\
\text { I did not have someone to support me in seeking and reaching } \\
\text { care at the fistula center. }\end{array}$ & \\
\hline $\begin{array}{l}\text { Internalized } \\
\text { stigma } \\
\text { (7-item) }\end{array}$ & $\begin{array}{l}\text { I felt ashamed of having fistula. } \\
\text { I felt worthless. } \\
\text { I felt guilty because I had fistula. } \\
\text { I felt I am not as complete as a person because I had fistula. } \\
\text { Having fistula made me feel unclean. } \\
\text { I felt embarrassed because of my condition. } \\
\text { I felt isolated because of my fistula condition. }\end{array}$ & \\
\hline
\end{tabular}

Financial and Transportation Inaccessibility Index

\begin{tabular}{ll}
\hline Item $(\mathrm{n}=6)$ & Response categories \\
\hline I did not have money to pay for medical care to treat my fistula & \\
I was unable to work because of stigma associated with my fistula condition & Strongly disagree \\
There are not enough transport options to get to the fistula center & Disagree \\
The cost of transportation to repair sites and accommodation was too high & $\begin{array}{l}\text { Agree } \\
\text { The repair facility was too far }\end{array}$ \\
The road conditions were bad & \\
\hline
\end{tabular}

Composite measure scores for all three sites show limited reduction from baseline to endline (Figure 7 , following page). Interestingly, barriers remained fairly consistent in all three sites and points in time, suggesting, despite differences in geography as well as social and cultural norms across northern and southern Nigeria and in Uganda, that barriers to fistula care are similar. Internalized stigma barriers emerge as the dominant and prevailing barriers to care, followed by financial and transportation inaccessibility.

Insufficient change is potentially due to the fact that clients interviewed at fistula centers included women from outside the intervention and comparison areas who likely were not exposed to the full intervention. The lower awareness and social abandonment barriers may be, at least partially, attributed to overall intervention and broader fistula programming in sites. 
Figure 7. Composite scores of barriers to care indices among post-repair fistula clients, by site

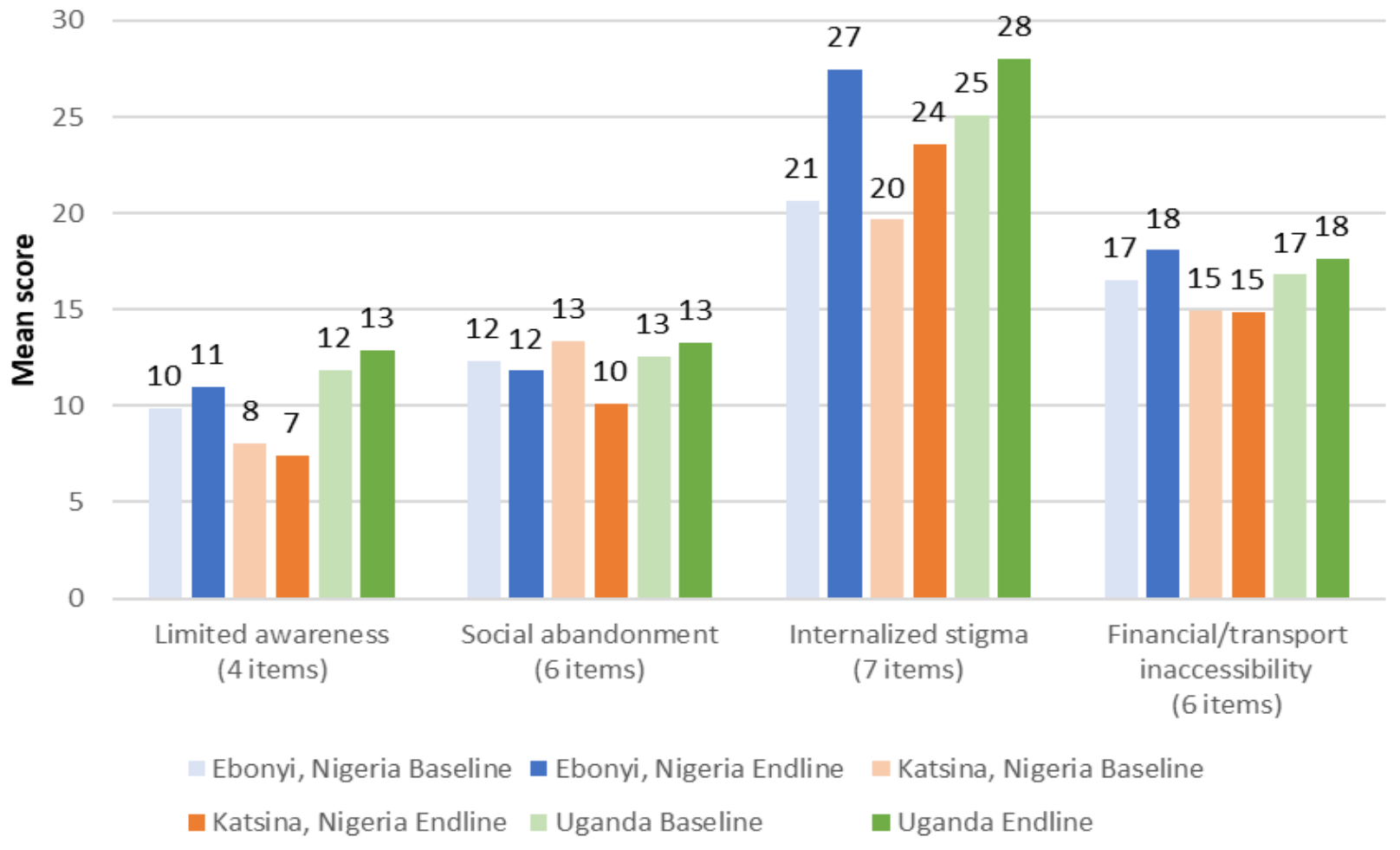

Qualitative focus groups at endline in all three study sites indicate that exposure to the intervention in some capacity had some normative community influence on reducing barriers to care, particularly for knowledge about the causes and consequences of fistula. There was some reduction in myths and misconceptions (e.g. that fistula is caused by promiscuity or witchcraft), better recognition of early marriage and prolonged labor as causes, as well as ability to identify iatrogenic and sexual causes. In all sites, communities expressed sympathy for women with fistula at endline, a broad attitudinal shift.

"We feel for others with such problems, to connect with medical team to help her and encourage her to get help."

Community woman, Uganda

While communities understand that fistula is treatable and are aware of treatment options in intervention areas and comparison areas (particularly in high prevalence areas like Katsina), they continue to report a range of barriers. In some sites (e.g. Uganda) leaders believe fistula can heal itself, and can influence community views, when expressed in sermons and village meetings.

Prevailing barriers relate to the shame and intimate nature of the condition, perceived and actual costs (related mostly to a companion), and perceived poor quality of fistula care (for prevention and treatment). Gender dynamics appear critical in influencing whether and when women can seek care for fistula.

"Ashamed...because it is only when they talk that people will know that they are suffering fistula, the person will not want people to know her condition, she will be dying silently...."

\section{Community woman, intervention, Ebonyi}

"Most of the victims of this [sic] problems are suffering from extreme poverty and used to beg for money in the mosques; if they were wealthy their situation would have never been escalated."

Community woman, Katsina, intervention 


\section{Focused training and job aids improve PHC provider abilities to diagnose and refer}

\section{Background characteristics of PHC providers}

Most providers in each intervention area were community health extension workers (CHEWs): 55 percent to 75 percent in Ebonyi, 38 percent to 50 percent in Katsina, and 60 percent to 65 percent in Uganda. (Table 8 presents the background characteristics of PHC providers surveyed within the intervention areas at baseline; Table A9 in appendix shows baseline and endline.) Other provider cadres interviewed included nurse and midwives, ranging from nine to 22 percent in Ebonyi, seven to 29 percent in Katsina, and seven to 14 percent in Katsina, along with community health officers (CHOs), from five to seven percent in Ebonyi, seven percent in Katsina, and 11 to 16 percent in Uganda. In Nigeria, nurses and midwives were the second most represented category of care providers, while in Uganda CHOs were the most prevalent alternative to CHEWs.

Overall, PHC providers in Nigeria had more experience and reported more in-service training than those in Uganda. In Nigeria, the median number of years of experience working as a provider ranged from six to 10 years in Ebonyi and 10 to 18 years in Katsina, while in Uganda the median was five years, in both intervention and comparison areas. In Uganda 30 percent to 40 percent of providers reported no relevant in-service training within the year preceding their interviews, while no providers in Nigeria reported lack of recent training.

In Nigeria, PHC providers in Ebonyi's intervention area reported slightly more training than those in Katsina's intervention area, especially at endline. In Katsina, less than half of providers had been trained on all relevant topics, whereas in both Ebonyi's intervention and comparison LGAs over half of providers reported in-service training on active management of third stage of labor, partograph use, basic newborn care, newborn resuscitation, high blood pressure, and eclampsia management. In Ebonyi's intervention LGA, the proportion of PHC providers who received in-service training on all topics was greater at endline than at baseline, while in Katsina's intervention LGA the proportions were greater at endline for only two training topics: use of partograph and management of obstructed labor. In Nigeria's comparison areas, a greater proportion of PHCs in Ebonyi at endline were trained in partograph use, with similar trends in obstructed labor training in Katsina. In Uganda, there were no differences in the proportions of PHC providers trained at baseline and endline for any topics, in both its intervention and comparison areas.

Table 8. Background characteristics of PHC providers at baseline

\begin{tabular}{|c|c|c|c|c|c|c|}
\hline & \multicolumn{2}{|c|}{ Ebonyi, Nigeria } & \multicolumn{2}{|c|}{ Katsina, Nigeria } & \multicolumn{2}{|c|}{ Central 1, Uganda } \\
\hline & 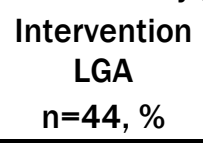 & $\begin{array}{c}\text { Comparison } \\
\text { LGA } \\
n=73, \% \\
\end{array}$ & 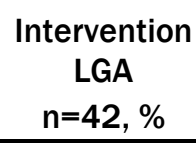 & $\begin{array}{c}\begin{array}{c}\text { Comparison } \\
\text { LGA } \\
n=46, \%\end{array} \\
\end{array}$ & 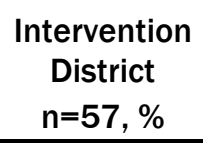 & $\begin{array}{c}\begin{array}{c}\text { Comparison } \\
\text { District } \\
n=62, \% \\
\end{array} \\
\end{array}$ \\
\hline \multicolumn{7}{|l|}{ Provider type } \\
\hline Medical officer & 6.8 & 6.8 & 9.5 & 2.2 & 0.0 & 3.2 \\
\hline Nurse/midwife & 9.1 & 21.9 & 28.6 & 6.5 & 14.0 & 6.5 \\
\hline CHEW & 75.0 & 54.8 & 38.1 & 50.0 & 64.9 & 59.7 \\
\hline $\mathrm{CHO}$ & 4.5 & 6.8 & 7.1 & 6.5 & 10.5 & 16.1 \\
\hline Nutritionist & 0.0 & 0.0 & 0.0 & 4.3 & 0.0 & 0.0 \\
\hline Social worker & 0.0 & 0.0 & 0.0 & 0.0 & 0.0 & 0.0 \\
\hline Other & 0.0 & 0.0 & 0.0 & 0.0 & 10.5 & 14.5 \\
\hline Missing & 4.5 & 9.6 & 16.7 & 30.4 & 0.0 & 0.0 \\
\hline
\end{tabular}


Table 8. Background characteristics of PHC providers at baseline

\begin{tabular}{|c|c|c|c|c|c|c|}
\hline & \multicolumn{2}{|c|}{ Ebonyi, Nigeria } & \multicolumn{2}{|c|}{ Katsina, Nigeria } & \multicolumn{2}{|c|}{ Central 1, Uganda } \\
\hline \multicolumn{7}{|l|}{ Years as provider } \\
\hline Median & 10.0 & 6.0 & 18.0 & 9.5 & 5.0 & 5.0 \\
\hline IQR & $3-20.5$ & $3-13$ & $11-24$ & $6-15$ & $5-5$ & $5-5$ \\
\hline \multicolumn{7}{|c|}{ Received in-service training within year } \\
\hline $\begin{array}{l}\text { Comprehensive } \\
\text { ANC }\end{array}$ & 13.6 & 23.3 & 35.7 & 17.4 & 17.5 & 8.1 \\
\hline $\begin{array}{l}\text { Management } \\
\text { of labor }\end{array}$ & 22.7 & 35.6 & 38.1 & 10.9 & 21.1 & 8.1 \\
\hline $\begin{array}{l}\text { Active } \\
\text { management } \\
\text { of } 3^{\text {rd }} \text { stage labor }\end{array}$ & 31.8 & 38.4 & 28.6 & 8.7 & 24.6 & 14.5 \\
\hline Partograph use & 22.7 & 31.5 & 26.2 & 13.0 & 26.3 & 16.1 \\
\hline $\begin{array}{l}\text { Essential newborn } \\
\text { care }\end{array}$ & 34.1 & 43.8 & 42.9 & 17.4 & 33.3 & 21.0 \\
\hline $\begin{array}{l}\text { Newborn } \\
\text { resuscitation }\end{array}$ & 34.1 & 46.6 & 31.0 & 4.3 & 33.3 & 22.6 \\
\hline $\begin{array}{l}\text { Special newborn } \\
\text { care }\end{array}$ & 15.9 & 30.1 & 26.2 & 4.3 & 19.3 & 11.3 \\
\hline $\begin{array}{l}\text { Comprehensive } \\
\text { PNC }\end{array}$ & 13.6 & 21.9 & 26.2 & 8.7 & 15.8 & 6.5 \\
\hline $\begin{array}{l}\text { Eclampsia } \\
\text { management }\end{array}$ & 27.3 & 34.2 & 40.5 & 15.2 & 19.3 & 16.1 \\
\hline $\begin{array}{l}\text { Magnesium } \\
\text { sulphate }\end{array}$ & 20.5 & 28.8 & 45.2 & 23.9 & 17.5 & 16.1 \\
\hline \multicolumn{7}{|l|}{ Management of: } \\
\hline $\begin{array}{l}\text { High blood } \\
\text { pressure }\end{array}$ & 18.2 & 26.0 & 35.7 & 10.9 & 24.6 & 11.3 \\
\hline Sepsis/infection & 11.4 & 21.9 & 21.4 & 2.2 & 19.3 & 8.1 \\
\hline $\begin{array}{l}\text { Obstructed } \\
\text { labor }\end{array}$ & 15.9 & 23.3 & 14.3 & 0.0 & 17.5 & 8.1 \\
\hline Family planning & 65.9 & 50.7 & 38.1 & 13.0 & 26.3 & 27.4 \\
\hline None & 0.0 & 0.0 & 0.0 & 0.0 & 29.8 & 40.3 \\
\hline
\end{tabular}

\section{PHC Provider knowledge and practices}

Overall, $\mathrm{PHC}$ provider awareness of $\mathrm{P} / \mathrm{OL}$ as a fistula cause was higher than awareness of urine and fecal leaking as symptoms during the postnatal period. Awareness of foul-smelling discharge as a sign of fistula during the postnatal period varied among the three sites, with greater awareness among PHC providers in Uganda. (Figures A1 to A3 in the appendix present PHC providers' knowledge about the fistula causes and symptoms at baseline and endline from the intervention and comparison areas of all three sites.)

Tables 9 through 11 (next page) demonstrate trended differences in PHC provider recognition of fistula signs from baseline to endline. Tables 12 through 14 (following page) provide the trended differences in $\mathrm{PHC}$ provider $\mathrm{P} / \mathrm{OL}$ and fistula knowledge and practice at baseline and endline. 
Table 9. Differences in PHC provider recognition of fistula signs in Ebonyi, Nigeria

\begin{tabular}{|c|c|c|c|c|c|c|c|c|c|c|c|c|}
\hline & \multirow{2}{*}{\multicolumn{3}{|c|}{$\begin{array}{c}\text { Intervention } \\
\text { Baseline }\end{array}$}} & & & & \multicolumn{6}{|c|}{ Comparison } \\
\hline & & & & \multicolumn{3}{|c|}{ Endline } & \multicolumn{3}{|c|}{ Baseline } & \multicolumn{3}{|c|}{ Endline } \\
\hline & $\mathrm{n}$ & M & SD & $\mathbf{n}$ & M & SD & $\mathrm{n}$ & M & SD & $\mathbf{n}$ & M & SD \\
\hline Labor lasting $>12$ hours & 21 & 0.48 & 0.51 & 22 & 0.48 & 0.51 & 25 & 0.34 & 0.48 & 12 & 0.22 & 0.42 \\
\hline Obstructed labor & 15 & 0.34 & 0.48 & 28 & 0.61 & 0.49 & 34 & 0.47 & 0.50 & 28 & 0.52 & 0.50 \\
\hline Foul-smelling discharge & 17 & 0.39 & 0.49 & 7 & 0.15 & 0.36 & 21 & 0.29 & 0.46 & 9 & 0.17 & 0.38 \\
\hline Leaking urine & 0 & 0.00 & 0.00 & 2 & 0.04 & 0.21 & 0 & 0.00 & 0.00 & 8 & 0.15 & 0.36 \\
\hline Leaking feces & 0 & 0.00 & 0.00 & 1 & 0.02 & 0.15 & 0 & 0.00 & 0.00 & 6 & 0.11 & 0.32 \\
\hline
\end{tabular}

Table 10. Differences in PHC provider recognition of fistula signs in Katsina, Nigeria

\begin{tabular}{|c|c|c|c|c|c|c|c|c|c|c|c|c|}
\hline & \multicolumn{6}{|c|}{ Intervention } & \multicolumn{6}{|c|}{ Comparison } \\
\hline & \multicolumn{3}{|c|}{ Baseline } & \multicolumn{3}{|c|}{ Endline } & \multicolumn{3}{|c|}{ Baseline } & \multicolumn{3}{|c|}{ Endline } \\
\hline & $\mathrm{n}$ & M & SD & $\mathrm{n}$ & M & SD & $\mathrm{n}$ & M & SD & $\mathrm{n}$ & M & SD \\
\hline Labor lasting $>12$ hours & 11 & 0.26 & 0.45 & 20 & 0.33 & 0.47 & 6 & 0.13 & 0.34 & 15 & 0.47 & 0.51 \\
\hline Obstructed labor & 14 & 0.33 & 0.48 & 33 & 0.54 & 0.50 & 9 & 0.20 & 0.40 & 10 & 0.31 & 0.47 \\
\hline Foul-smelling discharge & 1 & 0.02 & 0.15 & 9 & 0.15 & 0.36 & 3 & 0.07 & 0.25 & 3 & 0.09 & 0.30 \\
\hline Leaking urine & 2 & 0.05 & 0.22 & 5 & 0.08 & 0.28 & 4 & 0.09 & 0.28 & 6 & 0.19 & 0.40 \\
\hline Leaking feces & 1 & 0.02 & 0.15 & 1 & 0.02 & 0.13 & 2 & 0.04 & 0.21 & 0 & 0.00 & 0.00 \\
\hline
\end{tabular}

Table 11. Differences in PHC provider recognition of fistula signs in Uganda

\begin{tabular}{|c|c|c|c|c|c|c|c|c|c|c|c|c|}
\hline & \multicolumn{6}{|c|}{ Intervention } & \multicolumn{6}{|c|}{ Comparison } \\
\hline & \multicolumn{3}{|c|}{ Baseline } & \multicolumn{3}{|c|}{ Endline } & \multicolumn{3}{|c|}{ Baseline } & \multicolumn{3}{|c|}{ Endline } \\
\hline & $\mathbf{n}$ & M & SD & $\mathbf{n}$ & M & SD & $\mathrm{n}$ & M & SD & $\mathrm{n}$ & M & SD \\
\hline Labor lasting >12 hours & 14 & 0.25 & 0.43 & 27 & 0.68 & 0.47 & 19 & 0.31 & 0.46 & 16 & 0.27 & 0.45 \\
\hline Obstructed labor & 33 & 0.58 & 0.50 & 30 & 0.75 & 0.44 & 37 & 0.60 & 0.49 & 23 & 0.38 & 0.49 \\
\hline Foul-smelling discharge & 17 & 0.30 & 0.46 & 22 & 0.55 & 0.50 & 28 & 0.45 & 0.50 & 30 & 0.50 & 0.50 \\
\hline Leaking urine & 8 & 0.14 & 0.35 & 24 & 0.60 & 0.50 & 12 & 0.19 & 0.40 & 15 & 0.25 & 0.44 \\
\hline Leaking feces & 2 & 0.04 & 0.19 & 24 & 0.60 & 0.50 & 8 & 0.13 & 0.34 & 8 & 0.13 & 0.34 \\
\hline
\end{tabular}


Table 12. Differences in PHC provider knowledge of prolonged and obstructed labor and fistula in Ebonyi, Nigeria

\begin{tabular}{|c|c|c|c|c|c|c|c|c|c|c|c|c|}
\hline & \multicolumn{6}{|c|}{ Intervention } & \multicolumn{6}{|c|}{ Comparison } \\
\hline & \multicolumn{3}{|c|}{ Baseline } & \multicolumn{3}{|c|}{ Endline } & \multicolumn{3}{|c|}{ Baseline } & \multicolumn{3}{|c|}{ Endline } \\
\hline & $\mathrm{n}$ & M & SD & $\mathrm{n}$ & M & SD & $\mathrm{n}$ & M & SD & $\mathrm{n}$ & M & SD \\
\hline Proportion of providers who reported $\mathrm{P} / \mathrm{OL}$ among clients & 16 & 0.36 & 0.49 & 19 & 0.41 & 0.50 & 23 & 0.32 & 0.47 & 20 & 0.37 & 0.49 \\
\hline Ever seen patient(s) who leak urine or feces uncontrollably & 12 & 0.27 & 0.45 & 24 & 0.52 & 0.51 & 30 & 0.41 & 0.50 & 23 & 0.43 & 0.50 \\
\hline Ever had patient with fistula symptoms approach for treatment & 10 & 0.23 & 0.42 & 20 & 0.43 & 0.50 & 24 & 0.33 & 0.47 & 19 & 0.35 & 0.48 \\
\hline Ever referred any woman with fistula symptoms & 12 & 0.27 & 0.45 & 18 & 0.39 & 0.49 & 27 & 0.37 & 0.49 & 20 & 0.37 & 0.49 \\
\hline Believes obstetric fistula is treatable & 41 & 0.93 & 0.25 & 46 & 1.00 & 0.00 & 73 & 1.00 & 0.00 & 54 & 1.00 & 0.00 \\
\hline
\end{tabular}

Table 13. Differences in PHC provider knowledge of prolonged and obstructed labor and fistula in Katsina, Nigeria

\begin{tabular}{|c|c|c|c|c|c|c|c|c|c|c|c|c|}
\hline & \multicolumn{6}{|c|}{ Intervention } & \multicolumn{6}{|c|}{ Comparison } \\
\hline & \multicolumn{3}{|c|}{ Baseline } & \multicolumn{3}{|c|}{ Endline } & \multicolumn{3}{|c|}{ Baseline } & \multicolumn{3}{|c|}{ Endline } \\
\hline & $\mathbf{n}$ & $\mathbf{M}$ & SD & $\mathbf{n}$ & $\mathbf{M}$ & SD & $\mathbf{n}$ & M & SD & $\mathbf{n}$ & M & SD \\
\hline Proportion of providers who reported $\mathrm{P} / \mathrm{OL}$ among clients & 18 & 0.43 & 0.50 & 27 & 0.44 & 0.50 & 14 & 0.30 & 0.47 & 13 & 0.41 & 0.50 \\
\hline Ever seen patient(s) who leak urine or feces uncontrollably & 3 & 0.07 & 0.26 & 27 & 0.44 & 0.50 & 8 & 0.17 & 0.38 & 20 & 0.63 & 0.49 \\
\hline Ever had patient with fistula symptoms approach you for treatment & 4 & 0.10 & 0.30 & 18 & 0.30 & 0.46 & 6 & 0.13 & 0.34 & 14 & 0.44 & 0.50 \\
\hline Ever referred any woman with fistula symptoms & 6 & 0.14 & 0.35 & 18 & 0.30 & 0.46 & 9 & 0.20 & 0.40 & 9 & 0.28 & 0.46 \\
\hline Believes obstetric fistula is treatable & 39 & 0.93 & 0.26 & 60 & 0.98 & 0.00 & 45 & 0.98 & 0.15 & 30 & 0.94 & 0.00 \\
\hline
\end{tabular}

Table 14. Differences in PHC provider knowledge of prolonged and obstructed labor and fistula in Central 1, Uganda

\begin{tabular}{|l|c|c|c|c|c|c|c|c|c|c|c|c|}
\hline & \multicolumn{4}{|c|}{ Intervention } & \multicolumn{5}{c|}{ Comparison } \\
\hline & \multicolumn{3}{|c|}{ Baseline } & \multicolumn{3}{|c|}{ Endline } & \multicolumn{3}{|c|}{ Baseline } & \multicolumn{3}{|c|}{ Endline } \\
\hline & $\mathrm{n}$ & $\mathrm{M}$ & $\mathrm{SD}$ & $\mathrm{n}$ & $\mathrm{M}$ & $\mathrm{SD}$ & $\mathrm{n}$ & $\mathrm{M}$ & $\mathrm{SD}$ & $\mathrm{n}$ & $\mathrm{M}$ & $\mathrm{SD}$ \\
\hline Proportion of providers who reported P/OL among clients & 27 & 0.47 & 0.50 & 19 & 0.48 & 0.51 & 18 & 0.29 & 0.46 & 18 & 0.30 & 0.46 \\
\hline Ever seen patient(s) who leak urine or feces uncontrollably & 19 & 0.33 & 0.48 & 24 & 0.60 & 0.50 & 17 & 0.27 & 0.45 & 15 & 0.25 & 0.44 \\
\hline Ever had patient with fistula symptoms approach you for treatment & 16 & 0.28 & 0.45 & 15 & 0.38 & 0.49 & 13 & 0.21 & 0.41 & 16 & 0.27 & 0.45 \\
\hline Ever referred any woman with fistula symptoms & 18 & 0.32 & 0.47 & 15 & 0.38 & 0.49 & 14 & 0.23 & 0.42 & 15 & 0.25 & 0.44 \\
\hline Believes obstetric fistula is treatable & 56 & 0.98 & 0.13 & 39 & 0.98 & 0.16 & 62 & 1.00 & 0.00 & 60 & 1.00 & 0.00 \\
\hline
\end{tabular}


In Nigeria, PHC providers demonstrated moderate increased recognition of fistula causes and symptoms from baseline to endline, and in the intervention areas the proportion of PHC providers who recognized obstructed labor as a fistula risk in Ebonyi and in Katsina increased. There was also an increase in recognition of foul-smelling discharge as a potential sign of fistula in Katsina, while in Ebonyi the proportion decreased from baseline to endline. In Nigeria's comparison areas, the proportion of Ebonyi PHC providers who recognized fistula signs of urine leaking and fecal leaking increased, while in Katsina PHC providers who recognized labor lasting longer than 12 hours as a fistula cause increased.

In Uganda, intervention area PHC providers demonstrated strong increase in awareness of fistula causes and symptoms: The proportion of PHC providers who recognized labor lasting longer than 12 hours as a fistula cause increased, along with urine leaking, fecal leaking, and foul-smelling discharge. By contrast, in Uganda's comparison area PHC provider awareness of obstructed labor as a fistula risk decreased.

In Nigeria's Ebonyi intervention area, there were significant differences in the proportion of PHC providers who had ever seen patients leak urine or feces uncontrollably and ever had a patient with fistula symptoms approach them for treatment. In Katsina's intervention area, there were also differences in the proportion of PHC providers who had ever seen patients who leaked urine or feces uncontrollably, ever had a patient with fistula symptoms approach them for treatment, and who believed that obstetric fistula is treatable. In Katsina's comparison area there were also differences in the proportion of PHC providers who had ever seen patients leak urine or feces uncontrollably or ever had a patient with fistula symptoms approach them for treatment.

In Uganda's intervention area, there were differences in the proportion of PHC providers who had ever seen patients leak urine or feces uncontrollably.

\section{Training and job aids}

Qualitative data from implementing stakeholders indicate that trainings and job aids were applicable and effective in enhancing PHC providers' efforts to educate and inform community members about fistula, help women with fistula overcome stigma barriers, and refer women for care and treatment.

PHC providers reported ease in using the job aid to counsel women not only about fistula symptoms and treatment, but expectations for the $\mathrm{FC}+$ intervention, care referrals, along with managing their post-repair recovery.

"The job aid clearly outlines the causes of fistula, how to prevent it, and seek treatment." PHC provider intervention sites, endline, Uganda

PHC providers acknowledged clinical support from practical refresher training at fistula centers following midline evaluations.

"The training was so organized, and we were taught how to use the job aid, transport voucher and hotline."

PHC Provider, endline Katsina, Nigeria

While some PHC providers reported not using the job aids, others found them useful during their discussions with women about fistula, corroborating women's experiences.

"It was during my health talk that a woman received information and later came back to me, so we did the hotline calls, arranged for transport, and she went for treatment at the fistula center."

PHC provider, endline, Ebonyi, Nigeria 


\section{Community outreach agents and service providers effectively promote an efficient, community-based referral system}

Qualitative data reveal the integral roles of community outreach agents-CBO volunteers in Nigeria and VHTs in Uganda-in promoting efficient community-based referrals in all three settings, and integrating the hotline as a job aid for routine functions. In both countries, these agents characteristically perform home visits or hold community meetings, though in Nigeria community outreach agents directly referred women to fistula centers, while in Uganda they were referred through a PHC provider. In all study sites, community members reported familiarity with community outreach agents in their area and considered them appropriately positioned to provide education about fistula prevention and treatment, particularly with the fistula hotline.

While community members and post-repair clients mentioned radios, billboards, and posters as major sources of information for care options and were aware of the hotline, they often could not recall the number.

"More awareness should be raised so people know that [fistula repair] is happening. If somebody had not told me, I wouldn't have known that they are curing it here."

Post-repair client, endline, Ebonyi Nigeria

Community outreach agents and other program participants felt that intervention trainings enhanced their abilities to refer potential fistula sufferers, with the increased multi-sectoral involvement and roles clarification, and that health system coordination ameliorated challenges in identifying and referring fistula patients from remote areas.

"From the trainings, I have improved on my knowledge that in case a person develops a problem she has to seek medical attention beyond the health facility where she developed the problem from [iatrogenic]."

VHT, intervention site, endline, Uganda

"In the training they taught us about the voucher, illustrating that we would distribute them...they contain an MTN number through which the PHC provider first sends a message that she had received a fistula client. It also had our contacts as taxi operators on which they call in order to know that a client is at such a health facility...like an identification document...it identifies that she [client] is being taken to Kitovu for such and such a reason."

Transportation officer, midline, Uganda

"Prior to the intervention, it was difficult for staff to visit every village to identify those patients. But when the training was done it was helpful...because we needed these people...if the VHT identifies the patient the woman goes to the VHT, then she is taken to the facility and screened..." Health manager, intervention site, endline, Uganda

Despite local intervention progress, many respondents felt the referral system to treatment centersparticularly transportation and communication functions-should be strengthened for their sustainability.

"The ministry should avail an ambulance as well as install a telephone service between health facilities and the referral centers for PHC workers to call ahead when sending fistula clients for surgery...We need to improve on that and the facilitation [financial support] for the ambulance service..."

Health Manager, comparison site, endline, Uganda 


\section{Discussion}

\section{Key Findings}

This intervention demonstrated robust community member use of the telephone hotline for fistula screening, along with increased abilities by women to seek fistula care through digital health solutions, and shows that implementation of a complex SBC intervention that addresses barriers to fistula care is both feasible, in a controlled, properly resourced setting, as well as effective, when integrated with community-based health systems and partners. Digital screening services can effectively reach women living with fistula when complemented by community outreach messages, with mass media promotion, along with a telephone hotline accompanied by strong cellular service and phone ownership.

The hotline also proved useful in aiding fistula screening by community outreach agents, who then provided referral information. Both PHC providers and community agents demonstrated improvements in fistula recognition, in addition to referral knowledge and practice. Community attitudes towards women living with fistula also improved, with increased knowledge and support for women with fistula in the intervention areas.

Approximately three quarters of callers from all three sites screened positively for fistula, and fistula admissions and surgeries in increased at the fistula centers in the study areas. Applying models from prior research, this study estimates that the intervention identified about 200 fistula cases, approximately 15 percent of estimated fistula cases in Ebonyi state. ${ }^{14}$ Findings reveal similar fistula experience and care-seeking in the intervention and comparison areas, suggesting ancillary effects of a systems intervention, and digital health approaches.

This intervention demonstrated mixed results. Use of the transportation voucher mechanism varied, and demonstrated the need for stronger community referrals and formalized patient transportation. The intervention model was more influential in Ebonyi than in the other two intervention sites, plausibly due to its longer exposure time. Call volumes fluctuated, with the highest volume of calls in the first quarter of the intervention. While the intervention's results belie intervention challenges, those involved in the program, including actual and potential beneficiaries, agree on the importance of sustaining interventions that focus on fistula prevention and treatment.

\section{Limitations}

Real world sampling considerations limited the study's ability to collect comparative and sufficient subsamples and assess statistically significant changes from baseline to endline. PHC providers and postrepair fistula clients interviewed were not necessarily exposed to the intervention, and ultimately the number of respondents exposed to the intervention was not sufficient for certain analyses. At endline, half of the women in Katsina lived within the intervention area, whereas that percentage was 35 percent in Ebonyi and 15 percent in Uganda. Moreover, the vast majority of women treated in Katsina were from the state, both at baseline and endline, whereas in Ebonyi nearly two thirds of women at baseline, and slightly less than a half at endline, were from another state, and in Uganda nearly all of the women at baseline were from the Central 1 region, while over two thirds at endline were exogenous. The high attrition and changes in PHC providers in the three sites prevented accounting of any shared variance between baseline and endline groups via paired analysis. 
Other limitations are due to program fidelity, as the density of community outreach agents varied greatly by site due to existing community structures. In Nigeria, FC+ worked in Ebonyi and Katsina states on other activities, whereas in Uganda FC+ was more focused on Kalungu district, with greater possibility of ancillary intervention effects in Nigeria. Community outreach agents operated and provided free transportation throughout both states in Nigeria, and not only in intervention LGAs.

\section{Recommendations}

Assess the progress of the various commitments of stakeholders during research uptake meetings in every site to sustain "awareness-building" for fistula prevention and treatment.

- In Nigeria: The State Primary Health Care Development Agency (SPHCDA) expressed the intention of integrating training materials from the $\mathrm{FC}+\mathrm{SBC}$ package for orientation of PHC and secondary facilities, as well as health educators, in both Ebonyi and Katsina, which aligns with the national PHC Under One Roof Policy.

- In Ebonyi, assign a desk officer in each LGA level to link women to care and sustain NOFIC outreach.

- In Katsina, media outlets expressed interest in publicizing fistula care options through various media (television and radio).

- In Uganda: The Fistula Technical Working Group and MoH aimed to include these findings in the National Fistula Strategy as well as furthering VHT evidence relevant for the Community Health Strategy.

Include the screening hotline within broader national digital health platforms to ensure its sustainability and widely educate communities about fistula to shift care-seeking norms.

Consider utilizing and incorporating IVR to reach other stigmatized populations.

Explore alternatives to transportation vouchers, such social insurance, transport worker unions, eligibility for ambulance services, when vouchers are unsustainable or challenging to scale, to support access to fistula treatment.

Adapt and integrate simplified screening and referral tools within extant community health systems, especially for their use in communities and PHC centers.

Integrate final composite barrier measures ${ }^{15}$, including the financial and transportation inaccessibility index and multi-dimensional barrier to fistula care index, within routine fistula program monitoring efforts.

\section{Conclusion}

This research-to-action pilot demonstrates the feasibility of implementing a complex SBC intervention to address barriers to accessing fistula care along with the effectiveness integrated programming by community-based health systems and partners. Despite process challenges, promising trends emerged, in increased awareness among all stakeholders-women living with fistula to providers of community or facility-based care, to state officials-of the importance of sustaining interventions on prevention and treatment. Integration of digital screening services can be effective and have significant impacts and reach if coordinated with and reinforced by existing community programs and efforts. 


\section{References}

1. Keya KT, P Sripad, E Nwala CE Warren. 2018. "Poverty is the big thing": exploring financial, transportation, and opportunity costs associated with fistula management and repair in Nigeria and Uganda. Int J Equity Health 17: 70. doi.org/10.1186/s12939-018-0777-1

2. Baker Z, B Bellows, R Bach, C Warren. 2017. Barriers to obstetric fistula treatment in low-income countries: a systematic review. Trop Med Int Heal 22(8): 938-959.

3. Ijaiya MA, AG Rahman, AP Aboyeji, AW Olatinwo, SA Esuga, OK Ogah, HO Raji, IO Adebara, AO Akintobi, AS Adeniran, AA Adewole. 2010. Vesico vaginal fistula: a review of Nigerian experience. West Afr J Med 29(5): 293-298.

4. Uganda Bureau of Statistics (UBOS), ICF International Inc. 2012. Uganda Demographic and Health Survey 2011. Kampala: UBOS and Calverton, Maryland: ICF International Inc.

5. Uganda Bureau of Statistics (UBOS) and ICF International Inc. 2018. Uganda Demographic and Health Survey 2016. Kampala: UBOS and ICF. http://dhsprogram.com/pubs/pdf/FR333/FR333.pdf.

6. McCurdie FK, J Moffatt, K Jones. 2018. Vesicovaginal fistula in Uganda. J Obstet Gynaecol. 38(6): 822-827. doi.org/10.1080/01443615.2017.1407301

7. Bomboka J, M N-Mboowa, J Nakilembe. 2019. Post-effects of obstetric fistula in Uganda; a case study of fistula survivors in KITOVU mission hospital (MASAKA), Uganda. BMC Public Health 19: 696. doi.org/10.1186/s12889-019-7023-7

8. Barageine JK, NM Tumwesigye, JK Byamugisha, L Almroth, E Faxelid. 2014. Risk Factors for Obstetric Fistula in Western Uganda: A Case Control Study. PLoS ONE 9(11): e112299. doi.org/10.1371/journal.pone.0112299

9. Fiander A, C Ndahani, K Mmuya, T Vanneste. 2013. Results from 2011 for the transportMYpatient program for overcoming transport costs among women seeking treatment for obstetric fistula in Tanzania. Int J Gynaecol Obstet 120(3): 292-295.

10. MacDonald P, ME Stanton. 2007. USAID program for the prevention and treatment of vaginal fistula. Int J Gynaecol Obstet 99 Suppl 1: S112-6.

11. Lavender T, S Wakasiaka, L McGowan, M Moraa, J Omari, W Khisa. 2016. Secrecy inhibits support: A grounded theory of community perspectives of women suffering from obstetric fistula, in Kenya. Midwifery 42: 54-60.

12. Tripathi V, E Arnoff, P Sripad. Moving barriers to fistula care: Applying appreciative inquiry to improve access to screening and treatment in Nigeria and Uganda, Health Care for Women International, 41:5, 584-599. doi.org/10.1080/07399332.2019.1638924.

13. Uganda Bureau of Statistics. 2016. The National Population and Housing Census 2014: Sub-County Report. Kampala

14. Tripathi V, E Arnoff, B Bellows, P Sripad. 2019. Use of interactive voice response technology to address barriers to fistula care in Nigeria and Uganda. Mhealth 6. doi.org/10.21037/mhealth.2019.12.04.

15. Sripad P, E Arnoff, CE Warren, V Tripathi. Under Review. "Measuring barriers to fistula care: investigating composite measures for targeted fistula programming in Nigeria and Uganda." BMC Women's Health. 


\section{Appendices}

Table A1. Socio-demographic characteristics of post-repair fistula clients........................................31

Table A2. Economic capacity and autonomy of post-repair fistula clients.........................................32

Table A3. Marital characteristics of post-repair fistula clients ..............................................................33

Table A4. Reproductive health history of post-repair fistula clients ...................................................34

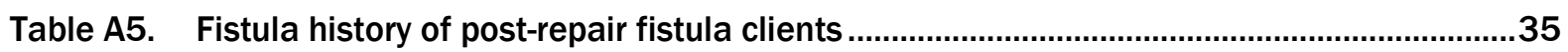

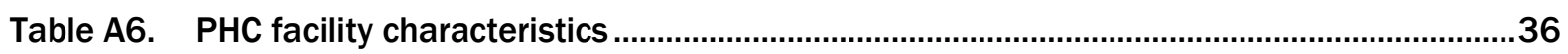

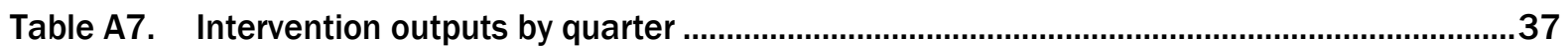

Table A8. Post repair fistula clients' experience with barriers to care .....................................................38

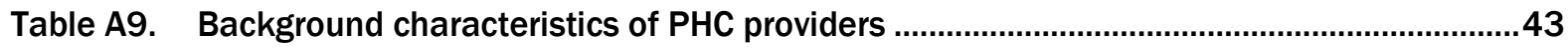

Table A10. PHC provider knowledge of and practices around prolonged or obstructed labor and genital fistula

Figure A1. PHC providers' knowledge change about fistula causes and symptoms (\%) in Ebonyi,

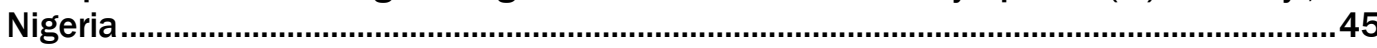

Figure A2. PHC providers' knowledge change about fistula causes and symptoms (\%) in Katsina,

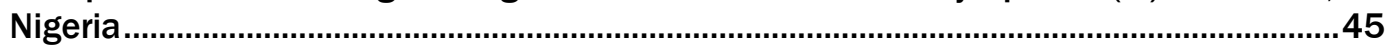

Figure A3. PHC providers' knowledge change about fistula causes and symptoms (\%) in Central 1

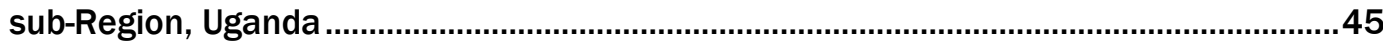


Table A1. Socio-demographic characteristics of post-repair fistula clients

\begin{tabular}{|c|c|c|c|c|c|c|}
\hline & \multicolumn{2}{|c|}{ Ebonyi, Nigeria } & \multicolumn{2}{|c|}{ Katsina, Nigeria } & \multicolumn{2}{|c|}{ Central 1, Uganda } \\
\hline & $\begin{array}{l}\text { Baseline } \\
\mathrm{n}=91, \%\end{array}$ & $\begin{array}{l}\text { Endline } \\
\mathrm{n}=51, \%\end{array}$ & $\begin{array}{l}\text { Baseline } \\
\mathrm{n}=81, \%\end{array}$ & $\begin{array}{l}\text { Endline } \\
\mathrm{n}=44, \%\end{array}$ & $\begin{array}{l}\text { Baseline } \\
\mathrm{n}=96, \%\end{array}$ & $\begin{array}{l}\text { Endline } \\
\mathrm{n}=47, \%\end{array}$ \\
\hline \multicolumn{7}{|l|}{ Residence } \\
\hline City / Town & 4.4 & 3.9 & 9.9 & 18.2 & 6.3 & 19.1 \\
\hline Rural area & 30.8 & 52.9 & 67.9 & 70.5 & 91.7 & 10.6 \\
\hline $\begin{array}{l}\text { Outside Ebonyi/ Katsina/ } \\
\text { Central-1 }\end{array}$ & 64.8 & 43.1 & 22.2 & 11.4 & 2.1 & 70.2 \\
\hline \multicolumn{7}{|l|}{ Intervention exposure } \\
\hline Lives w/in intervention area & & 35.3 & & 50.0 & & 14.9 \\
\hline Lives w/in comparison area & & 3.9 & & 2.3 & & 2.1 \\
\hline Lives outside int./comp. areas & & 11.8 & & 36.4 & & 83.0 \\
\hline \multicolumn{7}{|l|}{ Age } \\
\hline $15-25$ years & 17.6 & 17.6 & 49.4 & 45.5 & 34.4 & 25.5 \\
\hline $26-35$ years & 34.1 & 29.4 & 14.8 & 47.7 & 33.3 & 53.2 \\
\hline $36-45$ years & 25.3 & 21.6 & 0.0 & 2.3 & 21.9 & 12.8 \\
\hline 46-and above & 6.6 & 19.6 & 0.0 & 2.3 & 6.3 & 8.5 \\
\hline Missing & 16.5 & 11.8 & 35.8 & 2.3 & 4.2 & 0.0 \\
\hline \multicolumn{7}{|l|}{ Education } \\
\hline None & 12.1 & 31.4 & 37.0 & 68.2 & 13.5 & 4.3 \\
\hline Primary school & 27.5 & 41.2 & 13.6 & 9.1 & 64.6 & 78.7 \\
\hline Secondary school and more & 60.4 & 27.5 & 2.5 & 6.8 & 21.9 & 17.0 \\
\hline Quranic only & 0.0 & 0.0 & 46.9 & 15.9 & 0.0 & 0.0 \\
\hline \multicolumn{7}{|l|}{ Religion } \\
\hline Christian & 95.6 & 90.2 & 0.0 & 2.3 & 88.5 & 80.9 \\
\hline Muslim & 3.3 & 5.9 & 100.0 & 95.5 & 11.5 & 10.6 \\
\hline No religion & 1.1 & 2.0 & 0.0 & 0.0 & 0.0 & 0.0 \\
\hline Other & 0.0 & 2.0 & 0.0 & 2.3 & 0.0 & 4.3 \\
\hline Missing & 0.0 & 0.0 & 0.0 & 0.0 & 0.0 & 4.6 \\
\hline \multicolumn{7}{|l|}{ Ethnicity } \\
\hline Baganda & $\mathrm{N} / \mathrm{A}$ & $\mathrm{N} / \mathrm{A}$ & $\mathrm{N} / \mathrm{A}$ & $\mathrm{N} / \mathrm{A}$ & 44.8 & 44.7 \\
\hline Banyoro & $\mathrm{N} / \mathrm{A}$ & $\mathrm{N} / \mathrm{A}$ & $\mathrm{N} / \mathrm{A}$ & $\mathrm{N} / \mathrm{A}$ & 2.1 & 2.1 \\
\hline Banyankole & $\mathrm{N} / \mathrm{A}$ & N/A & N/A & $\mathrm{N} / \mathrm{A}$ & 20.8 & 19.1 \\
\hline Basoga & $\mathrm{N} / \mathrm{A}$ & N/A & $\mathrm{N} / \mathrm{A}$ & $\mathrm{N} / \mathrm{A}$ & 2.1 & 0.0 \\
\hline Bakiga & N/A & $\mathrm{N} / \mathrm{A}$ & N/A & $\mathrm{N} / \mathrm{A}$ & 6.3 & 8.5 \\
\hline Hausa & 1.1 & 3.9 & 65.4 & 65.9 & $\mathrm{~N} / \mathrm{A}$ & $\mathrm{N} / \mathrm{A}$ \\
\hline Igbo & 81.3 & 74.5 & 0.0 & 2.3 & N/A & $\mathrm{N} / \mathrm{A}$ \\
\hline Fulani & 0.0 & 0.0 & 28.4 & 29.5 & N/A & N/A \\
\hline Ibibio & 2.2 & 0.0 & 0.0 & 0.0 & N/A & $\mathrm{N} / \mathrm{A}$ \\
\hline Kanuri & 0.0 & 0.0 & 3.7 & 0.0 & $\mathrm{~N} / \mathrm{A}$ & $\mathrm{N} / \mathrm{A}$ \\
\hline Other & 13.2 & 17.6 & 2.5 & 2.3 & 24.0 & 21.3 \\
\hline Missing & 2.2 & 3.9 & 0.0 & 0.0 & 0.0 & 4.3 \\
\hline
\end{tabular}


Table A2. Economic capacity and autonomy of post-repair fistula clients

\begin{tabular}{lcccccc}
\hline & \multicolumn{2}{c}{ Ebonyi, Nigeria } & \multicolumn{2}{c}{ Katsina, Nigeria } & \multicolumn{2}{c}{ Central 1, Uganda } \\
& Baseline & Endline & Baseline & Endline & Baseline & Endline \\
& $\mathrm{n}=91, \%$ & $\mathrm{n}=51, \%$ & $\mathrm{n}=81, \%$ & $\mathrm{n}=\mathbf{4 4 , \%}$ & $\mathrm{n}=96, \%$ & $\mathrm{n}=47, \%$ \\
\hline Currently working & & & & & & \\
\hline Yes & 57.1 & 72.5 & 14.8 & 11.4 & 58.3 & 53.2 \\
No & 40.7 & 27.5 & 84.0 & 84.1 & 41.7 & 46.8 \\
Missing & 2.2 & 0.0 & 1.2 & 4.5 & 0.0 & 0.0 \\
\hline Worked for income in last year & & & & & & \\
\hline Yes & 41.8 & 21.6 & 8.6 & 25.0 & 12.5 & 2.1 \\
No & 58.2 & 37.3 & 91.4 & 63.6 & 29.2 & 44.7 \\
Missing & 0.0 & 41.2 & 0.0 & 11.4 & 58.3 & 53.2 \\
\hline Monthly income & & & & & & \\
\hline O - 5 USD & 0.0 & 0.0 & 0.0 & 0.0 & 2.1 & 4.3 \\
$5-10$ USD & 0.0 & 0.0 & 0.0 & 0.0 & 3.1 & 2.1 \\
10 - 15 USD & 18.7 & 17.6 & 14.8 & 18.2 & 3.3 & 6.4 \\
15 - 30 USD & 19.8 & 23.5 & 2.5 & 9.1 & 1.0 & 27.7 \\
30 - 50 USD & 11.0 & 11.8 & 0.0 & 0.0 & 3.1 & 2.1 \\
50 - 85 USD & 13.2 & 3.9 & 0.0 & 0.0 & 0.0 & 10.6 \\
Above 85 USD & 6.6 & 2.0 & 0.0 & 0.0 & 0.0 & 2.1 \\
Don't know & 9.9 & 0.0 & 2 & 0.0 & 0.0 & 0.0 \\
Missing & 20.9 & 41.2 & 80.2 & 72.7 & 87.5 & 44.7 \\
\hline Decision-making of money earned & & & & & & \\
\hline Self & 45.1 & 29.4 & 13.6 & 15.9 & 8.3 & 36.2 \\
Husband/partner & 6.6 & 5.9 & 3.7 & 4.5 & 3.1 & 8.5 \\
Self and husband/partner & 22.0 & 21.6 & 1.2 & 11.4 & 0.0 & 8.5 \\
jointly & 2.2 & 2.0 & 1.2 & 2.3 & 1.00 & 2.1 \\
Someone else & 3.3 & 0.0 & 0.0 & 0.0 & 0.0 & 0.0 \\
Not applicable & 20.9 & 41.2 & 80.2 & 65.9 & 87.5 & 44.7 \\
Missing & & & & & &
\end{tabular}


Table A3. Marital characteristics of post-repair fistula clients

\begin{tabular}{|c|c|c|c|c|c|c|}
\hline & \multicolumn{2}{|c|}{ Ebonyi, Nigeria } & \multicolumn{2}{|c|}{ Katsina, Nigeria } & \multicolumn{2}{|c|}{ Central 1, Uganda } \\
\hline & $\begin{array}{l}\text { Baseline } \\
n=91, \%\end{array}$ & $\begin{array}{c}\text { Endline } \\
\mathrm{n}=51, \%\end{array}$ & $\begin{array}{l}\text { Baseline } \\
n=81, \%\end{array}$ & $\begin{array}{c}\text { Endline } \\
n=44, \%\end{array}$ & $\begin{array}{l}\text { Baseline } \\
n=96, \%\end{array}$ & $\begin{array}{c}\text { Endline } \\
n=47, \%\end{array}$ \\
\hline \multicolumn{7}{|l|}{ Marital status } \\
\hline Single (never married) & 14.3 & 11.8 & 0.0 & 4.5 & 10.4 & 4.3 \\
\hline Cohabitating & 0.0 & 2.0 & 1.2 & 0.0 & 14.6 & 70.2 \\
\hline Married & 73.6 & 56.9 & 86.4 & 84.1 & 40.6 & 21.3 \\
\hline Separated/divorced & 3.3 & 11.8 & 12.3 & 4.5 & 29.2 & 4.3 \\
\hline Widowed & 8.8 & 17.6 & 0.0 & 0.0 & 5.2 & 0.0 \\
\hline Missing & 0.0 & 0.0 & 0.0 & 6.8 & 0.0 & 0.0 \\
\hline \multicolumn{7}{|l|}{ Partner cohabitating } \\
\hline Living with her & 62.6 & 49.0 & 71.6 & 72.7 & 0.0 & 0.0 \\
\hline Staying elsewhere & 13.2 & 7.8 & 16.0 & 15.9 & 0.0 & 0.0 \\
\hline Missing & 24.2 & 43.1 & 12.3 & 11.4 & 100.0 & 100.0 \\
\hline \multicolumn{7}{|l|}{ Partner has other wives } \\
\hline Yes & 19.8 & 45.1 & 51.9 & 47.7 & 21.9 & 27.7 \\
\hline No & 65.9 & 43.1 & 48.1 & 36.4 & 8.3 & 34.0 \\
\hline Don't know & 1.1 & 0.0 & 0.0 & 0.0 & 4.2 & 8.5 \\
\hline Missing & 13.2 & 11.8 & 0.0 & 15.9 & 65.6 & 29.8 \\
\hline \multicolumn{7}{|l|}{ Married by own choice } \\
\hline Yes & 75.8 & 82.4 & 65.4 & 79.5 & 81.3 & 44.7 \\
\hline No & 6.6 & 5.9 & 34.6 & 6.8 & 8.3 & 8.5 \\
\hline Missing & 17.6 & 11.8 & 0.0 & 13.6 & 10.4 & 46.8 \\
\hline \multicolumn{7}{|l|}{ Partner age difference } \\
\hline Younger & 3.3 & 0.0 & 0.0 & 0.0 & 0.0 & 0.0 \\
\hline About same age & 12.1 & 15.7 & 11.1 & 0.0 & 20.8 & 8.5 \\
\hline Older (by < 10 years) & 37.4 & 41.2 & 42.0 & 18.2 & 58.3 & 23.4 \\
\hline Older (by > 10 years) & 30.8 & 17.6 & 24.7 & 68.2 & 10.4 & 21.3 \\
\hline Don't know & 2.2 & 13.7 & 22.2 & 6.8 & 0.0 & 0.0 \\
\hline Missing & 14.3 & 11.8 & 0.0 & 6.8 & 10.4 & 4.3 \\
\hline \multicolumn{7}{|l|}{ Age at marriage } \\
\hline $1-10$ years & 1.1 & 2.0 & 1.2 & 0.0 & 0.0 & 0.0 \\
\hline $11-20$ years & 20.9 & 41.2 & 97.5 & 81.8 & 78.1 & 74.5 \\
\hline 21 - 30 years & 46.2 & 31.4 & 0.0 & 11.4 & 10.4 & 21.3 \\
\hline $31-40$ years & 2.2 & 0.0 & 0.0 & 0.0 & 0.0 & 0.0 \\
\hline Don't know & 8.8 & 13.7 & 1.2 & 0.0 & 1.0 & 0.0 \\
\hline Missing & 20.9 & 11.8 & 0.0 & 6.8 & 10.4 & 4.3 \\
\hline \multicolumn{7}{|l|}{ Husband's education } \\
\hline None & 9.9 & 13.7 & 11.1 & 63.6 & 8.3 & 6.4 \\
\hline Primary school & 20.9 & 41.2 & 1.2 & 4.5 & 41.7 & 57.4 \\
\hline Secondary school & 33.0 & 17.6 & 9.9 & 6.8 & 26.0 & 27.7 \\
\hline More than secondary & 9.9 & 13.7 & 8.6 & 9.1 & 5.2 & 2.1 \\
\hline Quranic only & 0.0 & 0.0 & 43.2 & 0.0 & 0.0 & 0.0 \\
\hline Don't know & 11.0 & 2.0 & 18.5 & 4.5 & 3.1 & 2.1 \\
\hline Missing & 15.4 & 11.8 & 7.4 & 11.4 & 15.6 & 4.3 \\
\hline
\end{tabular}




\begin{tabular}{|c|c|c|c|c|c|c|}
\hline & \multicolumn{2}{|c|}{ Ebonyi, Nigeria } & \multicolumn{2}{|c|}{ Katsina, Nigeria } & \multicolumn{2}{|c|}{ Central-1, Uganda } \\
\hline & $\begin{array}{l}\text { Baseline } \\
n=91, \%\end{array}$ & $\begin{array}{l}\text { Endline } \\
n=51, \%\end{array}$ & $\begin{array}{l}\text { Baseline } \\
n=81, \%\end{array}$ & $\begin{array}{l}\text { Endline } \\
n=44, \%\end{array}$ & $\begin{array}{l}\text { Baseline } \\
n=96, \%\end{array}$ & $\begin{array}{l}\text { Endline } \\
n=47, \%\end{array}$ \\
\hline \multicolumn{7}{|l|}{ Age at first sexual intercourse } \\
\hline $10-14$ years & 3.3 & 7.8 & 18.5 & 13.6 & 0.0 & 8.5 \\
\hline $15-19$ years & 50.5 & 51.0 & 77.8 & 81.8 & 86.5 & 78.7 \\
\hline $20-24$ years & 31.9 & 21.6 & 3.7 & 0.0 & 11.5 & 10.6 \\
\hline 25 years and above & 12.1 & 9.8 & 0.0 & 0.0 & 2.1 & 2.1 \\
\hline Missing & 2.2 & 9.8 & 0.0 & 4.5 & 0.0 & 0.0 \\
\hline \multicolumn{7}{|l|}{ Age at first pregnancy } \\
\hline $10-14$ years & 0.0 & 0.0 & 1.2 & 4.5 & 3.1 & 2.1 \\
\hline $15-19$ years & 20.9 & 31.4 & 90.1 & 84.1 & 69.8 & 63.8 \\
\hline $20-24$ years & 33.0 & 35.3 & 8.6 & 4.5 & 26.0 & 29.8 \\
\hline 25 years and above & 40.7 & 21.6 & 0.0 & 0.0 & 1.0 & 4.3 \\
\hline Missing & 5.5 & 11.8 & 0.0 & 6.8 & 0.0 & 0.0 \\
\hline \multicolumn{7}{|l|}{ Number of living children } \\
\hline None & 28.6 & 33.3 & 13.6 & 25.0 & 0.0 & 14.9 \\
\hline 1 & 26.4 & 21.6 & 14.8 & 20.5 & 43.8 & 14.9 \\
\hline 2 & 12.1 & 7.8 & 7.4 & 13.6 & 12.5 & 19.1 \\
\hline 3 & 8.8 & 9.8 & 11.1 & 11.4 & 14.6 & 21.3 \\
\hline 4 & 12.1 & 9.8 & 1.2 & 9.1 & 10.4 & 14.9 \\
\hline 5 or more & 9.9 & 11.8 & 9.9 & 13.6 & 17.7 & 14.9 \\
\hline Missing & 2.2 & 5.9 & 42.0 & 6.8 & 1.0 & 0.0 \\
\hline \multicolumn{7}{|c|}{ Attended ANC during last pregnancy } \\
\hline Yes & 81.3 & 66.7 & 55.6 & 52.3 & 96.9 & 95.7 \\
\hline No & 15.4 & 27.5 & 44.4 & 34.1 & 3.1 & 4.3 \\
\hline Missing & 3.3 & 5.9 & 0.0 & 13.6 & 0.0 & 0.0 \\
\hline \multicolumn{7}{|l|}{ Last pregnancy delivered at: } \\
\hline Hospital/facility/PHC & 85.7 & 56.9 & 80.2 & 77.3 & 88.5 & 91.5 \\
\hline Home & 2.2 & 21.6 & 17.3 & 6.8 & 6.3 & 6.4 \\
\hline Home with TBA & 1.1 & 17.6 & 0.0 & 9.1 & 5.2 & 2.1 \\
\hline Missing & 11.0 & 3.9 & 2.5 & 6.8 & 0.0 & 0.0 \\
\hline \multicolumn{7}{|l|}{ Complications during last delivery } \\
\hline Yes & 83.5 & 64.7 & 93.8 & 88.6 & 78.1 & 76.6 \\
\hline Bleeding & 20.9 & 5.9 & 2.5 & 9.1 & 29.2 & 31.9 \\
\hline Prolonged labor & 61.5 & 51.0 & 86.4 & 75.0 & 64.6 & 68.1 \\
\hline Fitting & 0.0 & 3.9 & 3.7 & 4.5 & 18.8 & 23.4 \\
\hline Sepsis & 0.0 & 2.0 & 1.2 & 0.0 & 20.8 & 10.6 \\
\hline Other & 1.1 & 2.0 & 0.0 & 0.0 & 8.3 & 0.0 \\
\hline None & 0.0 & 0.0 & 0.0 & 0.0 & 21.9 & 23.4 \\
\hline Missing & 16.5 & 35.3 & 6.2 & 11.4 & 0.0 & 0.0 \\
\hline \multicolumn{7}{|l|}{ Delivery outcome } \\
\hline Live baby & 24.2 & 29.4 & 14.8 & 13.6 & 49.0 & 61.7 \\
\hline $\begin{array}{l}\text { Live baby but died few hours } \\
\text { later }\end{array}$ & 19.8 & 15.7 & 6.2 & 25.0 & 13.5 & 8.5 \\
\hline Stillbirth & 52.7 & 51.0 & 79.0 & 54.50 & 37.5 & 29.8 \\
\hline Missing & 3.3 & 3.9 & 0.0 & 6.8 & 0.0 & 0.0 \\
\hline
\end{tabular}




\begin{tabular}{|c|c|c|c|c|c|c|}
\hline & \multicolumn{2}{|c|}{ Ebonyi, Nigeria } & \multicolumn{2}{|c|}{ Katsina, Nigeria } & \multicolumn{2}{|c|}{ Central-1, Uganda } \\
\hline & $\begin{array}{l}\text { Baseline } \\
n=91, \%\end{array}$ & $\begin{array}{l}\text { Endline } \\
n=51, \%\end{array}$ & $\begin{array}{l}\text { Baseline } \\
n=81, \%\end{array}$ & $\begin{array}{l}\text { Endline } \\
n=44, \%\end{array}$ & $\begin{array}{l}\text { Baseline } \\
n=96, \%\end{array}$ & $\begin{array}{l}\text { Endline } \\
n=47, \%\end{array}$ \\
\hline \multicolumn{7}{|l|}{ Length of time living with fistula } \\
\hline Less than a year & 49.5 & 19.6 & 59.3 & 81.8 & 41.7 & 48.9 \\
\hline $1-2$ years & 23.1 & 25.5 & 27.2 & 9.1 & 13.5 & 14.9 \\
\hline $3-4$ years & 8.8 & 17.6 & 4.9 & 2.3 & 6.3 & 8.5 \\
\hline $15-10$ years & 11.0 & 11.8 & 4.9 & 2.3 & 12.5 & 12.8 \\
\hline $10+$ years & 7.7 & 19.6 & 3.7 & 4.5 & 25.0 & 14.9 \\
\hline Missing & 0.0 & 5.9 & 0.0 & 0.0 & 1.0 & 0.0 \\
\hline \multicolumn{7}{|l|}{ Problem of leaking started } \\
\hline After delivering a live or stillborn baby & 84.6 & 88.2 & 98.8 & 95.5 & 87.5 & 97.9 \\
\hline After abdominal/pelvic surgery (pregnant) & 0.0 & 0.0 & 0.0 & 0.0 & 7.3 & 2.1 \\
\hline After abdominal/pelvic surgery (not pregnant) & 8.8 & 2.0 & 0.0 & 0.0 & 2.1 & 0.0 \\
\hline After a sexual assault or other injury & 1.1 & 0.0 & 1.2 & 0.0 & 0.0 & 0.0 \\
\hline From birth & 0.0 & 0.0 & 0.0 & 0.0 & 3.1 & 0.0 \\
\hline None of the above & 5.5 & 5.9 & 0.0 & 2.3 & 0.0 & 0.0 \\
\hline Don't know & 0.0 & 3.9 & 0.0 & 0.0 & 0.0 & 0.0 \\
\hline Missing & 0.0 & 0.0 & 0.0 & 2.3 & 0.0 & 0.0 \\
\hline \multicolumn{7}{|l|}{ Delivery after leaking started was } \\
\hline Normal delivery & 31.9 & 47.1 & 40.7 & 25.0 & 29.2 & 34.0 \\
\hline Assisted vaginal delivery & 6.6 & 3.9 & 34.6 & 27.3 & 17.7 & 17.0 \\
\hline Cesarean section & 61.5 & 41.2 & 24.7 & 43.2 & 38.5 & 46.8 \\
\hline Abdominal surgery (ruptured uterus) & 0.0 & 0.0 & 0.0 & 0.0 & 2.1 & 0.0 \\
\hline Missing & 0.0 & 7.8 & 0.0 & 4.5 & 12.5 & 2.1 \\
\hline \multicolumn{7}{|l|}{ Ever sought treatment for leaking previously } \\
\hline Yes & 27.5 & 45.1 & 48.1 & 43.2 & 54.2 & 59.6 \\
\hline No & 72.5 & 52.9 & 51.9 & 56.8 & 45.8 & 40.4 \\
\hline Missing & 0.0 & 2.0 & 0.0 & 0.0 & 0.0 & 0.0 \\
\hline \multicolumn{7}{|l|}{ Previously sought treatment from: } \\
\hline Health professional & 25.3 & 23.5 & 23.5 & 27.3 & 46.9 & 57.4 \\
\hline Community or village health worker & 1.1 & 2.0 & 0.0 & 11.4 & 0.0 & 0.0 \\
\hline Traditional /spiritual healer or other provider & 0.0 & 19.6 & 22.2 & 4.5 & 7.3 & 2.1 \\
\hline Other & 1.1 & 0.0 & 1.2 & 0.0 & 0.0 & 0.0 \\
\hline Not applicable & 72.5 & 52.9 & 51.9 & 56.8 & 45.8 & 40.4 \\
\hline Missing & 0.0 & 2.0 & 1.2 & 0.0 & 0.0 & 0.0 \\
\hline \multicolumn{7}{|l|}{ Previous treatment involved surgery } \\
\hline Yes & 8.8 & 9.8 & 13.6 & 18.2 & 12.5 & 19.1 \\
\hline No & 17.6 & 35.3 & 34.6 & 22.7 & 41.7 & 40.4 \\
\hline Not applicable & 72.5 & 52.9 & 51.9 & 56.8 & 45.8 & 40.4 \\
\hline Missing & 1.1 & 2.0 & 0.0 & 2.3 & 0.0 & 0.0 \\
\hline \multicolumn{7}{|l|}{ Number of times sought previously treatment } \\
\hline 1 & 14.3 & 13.7 & 11.1 & 4.5 & 17.7 & 23.4 \\
\hline 2 & 6.6 & 7.8 & 18.5 & 9.1 & 11.5 & 25.5 \\
\hline 3 & 1.1 & 3.9 & 8.6 & 6.8 & 8.3 & 2.1 \\
\hline 4 & 2.2 & 2.0 & 1.2 & 2.3 & 5.2 & 4.3 \\
\hline 5 or more & 0.0 & 3.9 & 4.9 & 15.9 & 11.5 & 2.1 \\
\hline Not applicable & 72.5 & 52.9 & 51.9 & 56.8 & 45.8 & 40.4 \\
\hline Missing & 3.3 & 15.7 & 3.7 & 4.5 & 0.0 & 2.1 \\
\hline
\end{tabular}




\begin{tabular}{|c|c|c|c|c|c|c|}
\hline & \multicolumn{2}{|c|}{$\begin{array}{c}\text { Intervention LGA } \\
\text { Ebonyi, Nigeria }\end{array}$} & \multicolumn{2}{|c|}{$\begin{array}{l}\text { Intervention LGA } \\
\text { Katsina, Nigeria }\end{array}$} & \multicolumn{2}{|c|}{$\begin{array}{l}\text { Intervention District } \\
\text { Central 1, Uganda }\end{array}$} \\
\hline & $\begin{array}{l}\text { Baseline } \\
n=39, \%\end{array}$ & $\begin{array}{l}\text { Endline } \\
\mathrm{n}=38, \%\end{array}$ & $\begin{array}{l}\text { Baseline } \\
n=37, \%\end{array}$ & $\begin{array}{l}\text { Endline } \\
\mathrm{n}=31, \%\end{array}$ & $\begin{array}{l}\text { Baseline } \\
n=50, \%\end{array}$ & $\begin{array}{l}\text { Endline } \\
\mathrm{n}=43, \%\end{array}$ \\
\hline \multicolumn{7}{|l|}{ Ownership } \\
\hline Public & 92.3 & 92.1 & 91.9 & 90.3 & 68.0 & 69.8 \\
\hline Private & 7.7 & 7.9 & 8.1 & 9.7 & 32.0 & 30.2 \\
\hline \multicolumn{7}{|l|}{ Facility capacity, has functional: } \\
\hline Private delivery room & 82.1 & 76.3 & 62.2 & 64.5 & 48.0 & 62.8 \\
\hline Theater equipment & 12.8 & 18.4 & 21.6 & 25.8 & 10.0 & 11.6 \\
\hline Infection prevention supplies & 43.6 & 23.7 & 59.5 & 58.1 & 72.0 & 76.7 \\
\hline Running water & 66.7 & 47.4 & 27.0 & 61.3 & 62.0 & 97.7 \\
\hline Fridge & 59.0 & 50.0 & 48.6 & 54.8 & 66.0 & 95.3 \\
\hline Toilet & 51.3 & 36.8 & 67.6 & 74.2 & 96.0 & 100.0 \\
\hline Electricity & 28.2 & 18.4 & 70.3 & 58.1 & 62.0 & 58.1 \\
\hline Generator & 46.2 & 44.7 & 43.2 & 48.4 & 18.0 & 25.6 \\
\hline Experiences power outages & 64.1 & 65.8 & 51.4 & 58.1 & 40.0 & 20.9 \\
\hline
\end{tabular}


Table A7. Intervention outputs by quarter

\begin{tabular}{|c|c|c|c|c|c|c|c|c|c|c|c|c|c|c|c|c|c|c|c|c|c|c|c|}
\hline & \multirow{2}{*}{\multicolumn{3}{|c|}{$\begin{array}{c}\text { Q2 } 2017 \\
\text { (June only) } \\
\text { Nigeria }\end{array}$}} & \multicolumn{5}{|c|}{ Q3 2017} & \multicolumn{5}{|c|}{ Q4 2017} & \multicolumn{5}{|c|}{ Q1 2018} & \multicolumn{5}{|c|}{$\begin{array}{c}\text { Q2 } 2018 \\
\text { (April only for Nigeria) }\end{array}$} \\
\hline & & & & \multicolumn{3}{|c|}{ Nigeria } & \multicolumn{2}{|c|}{ Uganda } & \multicolumn{3}{|c|}{ Nigeria } & \multicolumn{2}{|c|}{ Uganda } & \multicolumn{3}{|c|}{ Nigeria } & \multicolumn{2}{|c|}{ Uganda } & \multicolumn{3}{|c|}{ Nigeria } & \multicolumn{2}{|c|}{ Uganda } \\
\hline & EB & KT & $\pi$ & EB & KT & $\pi$ & $\mathrm{KL}$ & $\pi$ & EB & KT & $\pi$ & $\mathrm{KL}$ & $\pi$ & EB & KT & $\pi$ & $\mathrm{KL}$ & $\pi$ & EB & KT & $\pi$ & $\mathrm{KL}$ & $\pi$ \\
\hline $\begin{array}{l}\text { Number of unique callers to fistula } \\
\text { screening hotline }\end{array}$ & - & - & $\begin{array}{c}11 \\
8\end{array}$ & - & - & $\begin{array}{c}37 \\
5\end{array}$ & - & $\begin{array}{c}19 \\
5\end{array}$ & - & - & $\begin{array}{c}33 \\
7\end{array}$ & - & $\begin{array}{c}18 \\
3\end{array}$ & - & - & $\begin{array}{c}32 \\
2\end{array}$ & - & $\begin{array}{c}10 \\
6\end{array}$ & - & - & 53 & - & $\begin{array}{c}11 \\
0\end{array}$ \\
\hline $\begin{array}{l}\text { Number of callers completing key } \\
\text { screening and location question }\end{array}$ & 37 & - & 64 & 97 & 59 & $\begin{array}{c}19 \\
7\end{array}$ & 43 & $\begin{array}{c}10 \\
6\end{array}$ & 86 & 53 & $\begin{array}{c}16 \\
8\end{array}$ & 25 & 93 & 74 & 25 & $\begin{array}{c}12 \\
9\end{array}$ & 20 & 60 & 7 & 7 & 14 & 33 & 62 \\
\hline $\begin{array}{l}\text { Number of callers screened } \\
\text { positively for fistula }\end{array}$ & 28 & - & 46 & 71 & 36 & $\begin{array}{c}12 \\
5\end{array}$ & 31 & 68 & 70 & 38 & $\begin{array}{c}12 \\
0\end{array}$ & 18 & 67 & 54 & 22 & 93 & 12 & 30 & 5 & 5 & 10 & 25 & 40 \\
\hline $\begin{array}{l}\text { Number of women referred to fistula } \\
\text { repair center and utilized transport } \\
\text { voucher mechanism } \\
\text { * Nigeria intervention LGAs only }\end{array}$ & 1 & - & - & 13 & 0 & - & 10 & - & 2 & 1 & - & 4 & - & 1 & 2 & - & 6 & - & 0 & 0 & - & 7 & - \\
\hline $\begin{array}{l}\text { Number of women referred through } \\
\text { intervention and diagnosed (with } \\
\text { fistula) at fistula repair center }\end{array}$ & $\begin{array}{c}4 \\
(3)\end{array}$ & - & - & $\begin{array}{l}76 \\
(3 \\
6)\end{array}$ & $\begin{array}{l}49 \\
(3 \\
3)\end{array}$ & - & $\begin{array}{l}15 \\
(7)\end{array}$ & - & $\begin{array}{l}29 \\
(1 \\
2)\end{array}$ & $\begin{array}{l}26 \\
(1 \\
2)\end{array}$ & - & $\begin{array}{c}0 \\
(0)\end{array}$ & - & $\begin{array}{r}7 \\
(3)\end{array}$ & $\begin{array}{l}20 \\
(7)\end{array}$ & - & $\begin{array}{l}20 \\
(1 \\
2)\end{array}$ & - & $\begin{array}{r}2 \\
(0)\end{array}$ & $\begin{array}{r}4 \\
(0)\end{array}$ & - & $\begin{array}{c}6 \\
(3)\end{array}$ & - \\
\hline $\begin{array}{l}\text { Number of women referred through } \\
\text { intervention and received fistula } \\
\text { treatment at fistula repair center }\end{array}$ & 2 & - & - & 21 & 23 & - & 5 & - & 10 & 12 & - & 0 & - & 2 & 4 & - & 11 & - & 0 & 0 & - & 3 & - \\
\hline
\end{tabular}

$\mathrm{EB}=$ Ebonyi, $\mathrm{KT}=$ Katsina, $\mathrm{KL}=\mathrm{Kalungu}, \mathrm{TT}=$ Total 
Table A8. Post repair fistula clients' experience with barriers to care

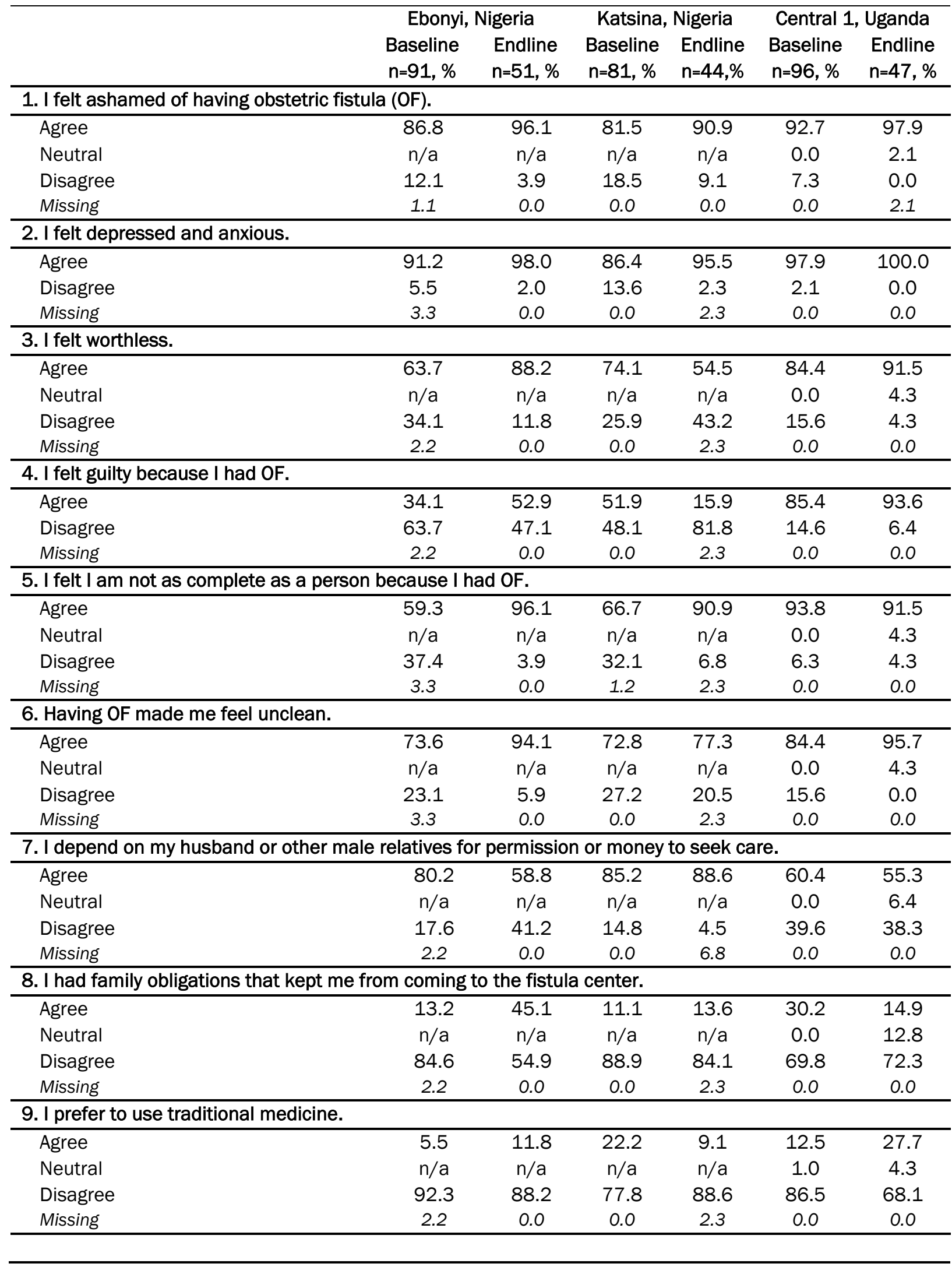




\begin{tabular}{|c|c|c|c|c|c|c|}
\hline & \multicolumn{2}{|c|}{ Ebonyi, Nigeria } & \multicolumn{2}{|c|}{ Katsina, Nigeria } & \multicolumn{2}{|c|}{ Central 1, Uganda } \\
\hline & $\begin{array}{l}\text { Baseline } \\
n=91, \%\end{array}$ & $\begin{array}{l}\text { Endline } \\
n=51, \%\end{array}$ & $\begin{array}{l}\text { Baseline } \\
n=81, \%\end{array}$ & $\begin{array}{l}\text { Endline } \\
n=44, \%\end{array}$ & $\begin{array}{l}\text { Baseline } \\
n=96, \%\end{array}$ & $\begin{array}{l}\text { Endline } \\
\mathrm{n}=47, \%\end{array}$ \\
\hline \multicolumn{7}{|c|}{ 10. I fear or dislike hospitals and medical clinics. } \\
\hline Agree & 16.5 & 19.6 & 8.6 & 20.5 & 4.2 & 14.9 \\
\hline Neutral & $\mathrm{n} / \mathrm{a}$ & $\mathrm{n} / \mathrm{a}$ & $\mathrm{n} / \mathrm{a}$ & $\mathrm{n} / \mathrm{a}$ & 1.0 & 4.3 \\
\hline Disagree & 81.3 & 80.4 & 91.4 & 77.3 & 94.8 & 80.9 \\
\hline Missing & 2.2 & 0.0 & 0.0 & 2.3 & 0.0 & 0.0 \\
\hline \multicolumn{7}{|c|}{ 11. I felt embarrassed because of my condition. } \\
\hline Agree & 86.8 & 90.2 & 51.9 & 81.8 & 93.8 & 95.7 \\
\hline Disagree & 11.0 & 9.8 & 48.1 & 15.9 & 6.3 & 4.3 \\
\hline Missing & 2.2 & 0.0 & 0.0 & 2.3 & 0.0 & 0.0 \\
\hline \multicolumn{7}{|c|}{ 12. I felt isolated because of my OF condition. } \\
\hline Agree & 63.7 & 76.5 & 55.6 & 79.5 & 69.8 & 63.8 \\
\hline Neutral & $\mathrm{n} / \mathrm{a}$ & $\mathrm{n} / \mathrm{a}$ & $\mathrm{n} / \mathrm{a}$ & $\mathrm{n} / \mathrm{a}$ & 0.0 & 10.6 \\
\hline Disagree & 30.8 & 23.5 & 44.4 & 18.2 & 30.2 & 25.5 \\
\hline Missing & 5.5 & 0.0 & 0.0 & 2.3 & 0.0 & 0.0 \\
\hline \multicolumn{7}{|c|}{ 13. People who knew I had OF avoided me. } \\
\hline Agree & 48.4 & 60.8 & 45.7 & 47.7 & 55.2 & 42.6 \\
\hline Neutral & $\mathrm{n} / \mathrm{a}$ & $\mathrm{n} / \mathrm{a}$ & $\mathrm{n} / \mathrm{a}$ & $\mathrm{n} / \mathrm{a}$ & 1.0 & 8.5 \\
\hline Disagree & 49.5 & 39.2 & 54.3 & 50.0 & 43.8 & 48.9 \\
\hline Missing & 2.2 & 0.0 & 0.0 & 2.3 & 0.0 & 0.0 \\
\hline \multicolumn{7}{|c|}{ 14. Women with OF are treated like outcasts. } \\
\hline Agree & 50.5 & 66.7 & 87.7 & 68.2 & 84.4 & 89.4 \\
\hline Neutral & $\mathrm{n} / \mathrm{a}$ & $\mathrm{n} / \mathrm{a}$ & $\mathrm{n} / \mathrm{a}$ & $\mathrm{n} / \mathrm{a}$ & 0.0 & 4.3 \\
\hline Disagree & 47.3 & 33.3 & 12.3 & 29.5 & 15.6 & 6.4 \\
\hline Missing & 2.2 & 0.0 & 0.0 & 2.3 & 0.0 & 0.0 \\
\hline \multicolumn{7}{|c|}{ 15. My husband/intimate partner treated me poorly initially. } \\
\hline Agree & 23.1 & 43.1 & 37.0 & 9.1 & 26.0 & 27.7 \\
\hline Neutral & $\mathrm{n} / \mathrm{a}$ & $\mathrm{n} / \mathrm{a}$ & $\mathrm{n} / \mathrm{a}$ & $\mathrm{n} / \mathrm{a}$ & 0.0 & 6.4 \\
\hline Disagree & 72.5 & 56.9 & 61.7 & 81.8 & 74.0 & 66.0 \\
\hline Missing & 4.4 & 0.0 & 1.2 & 9.1 & 0.0 & 0.0 \\
\hline \multicolumn{7}{|c|}{ 16. My husband/intimate partner treated me poorly later on. } \\
\hline Agree & 18.7 & 41.2 & 28.4 & 9.1 & 38.5 & 38.3 \\
\hline Neutral & $\mathrm{n} / \mathrm{a}$ & $\mathrm{n} / \mathrm{a}$ & $\mathrm{n} / \mathrm{a}$ & $\mathrm{n} / \mathrm{a}$ & 0.0 & 8.5 \\
\hline Disagree & 76.9 & 58.8 & 71.6 & 84.1 & 61.5 & 53.2 \\
\hline Missing & 4.4 & 0.0 & 0.0 & 6.8 & 0.0 & 0.0 \\
\hline \multicolumn{7}{|c|}{ 17. My husband/intimate partner abandoned me. } \\
\hline Agree & 16.5 & 45.1 & 22.2 & 9.1 & 34.4 & 31.9 \\
\hline Neutral & $\mathrm{n} / \mathrm{a}$ & $\mathrm{n} / \mathrm{a}$ & $\mathrm{n} / \mathrm{a}$ & $\mathrm{n} / \mathrm{a}$ & 0.0 & 4.3 \\
\hline Disagree & 78.0 & 54.9 & 76.5 & 84.1 & 65.6 & 63.8 \\
\hline Missing & 5.5 & 0.0 & 1.2 & 6.8 & 0.0 & 0.0 \\
\hline \multicolumn{7}{|c|}{ 18. I did not have someone to care for me and help me manage my condition at home. } \\
\hline Agree & 18.7 & 43.1 & 14.8 & 2.3 & 42.7 & 38.3 \\
\hline Neutral & $\mathrm{n} / \mathrm{a}$ & $\mathrm{n} / \mathrm{a}$ & $\mathrm{n} / \mathrm{a}$ & $\mathrm{n} / \mathrm{a}$ & 0.0 & 6.4 \\
\hline Disagree & 79.1 & 56.9 & 85.2 & 95.5 & 57.3 & 55.3 \\
\hline Missing & 2.2 & 0.0 & 0.0 & 2.3 & 0.0 & 0.0 \\
\hline
\end{tabular}




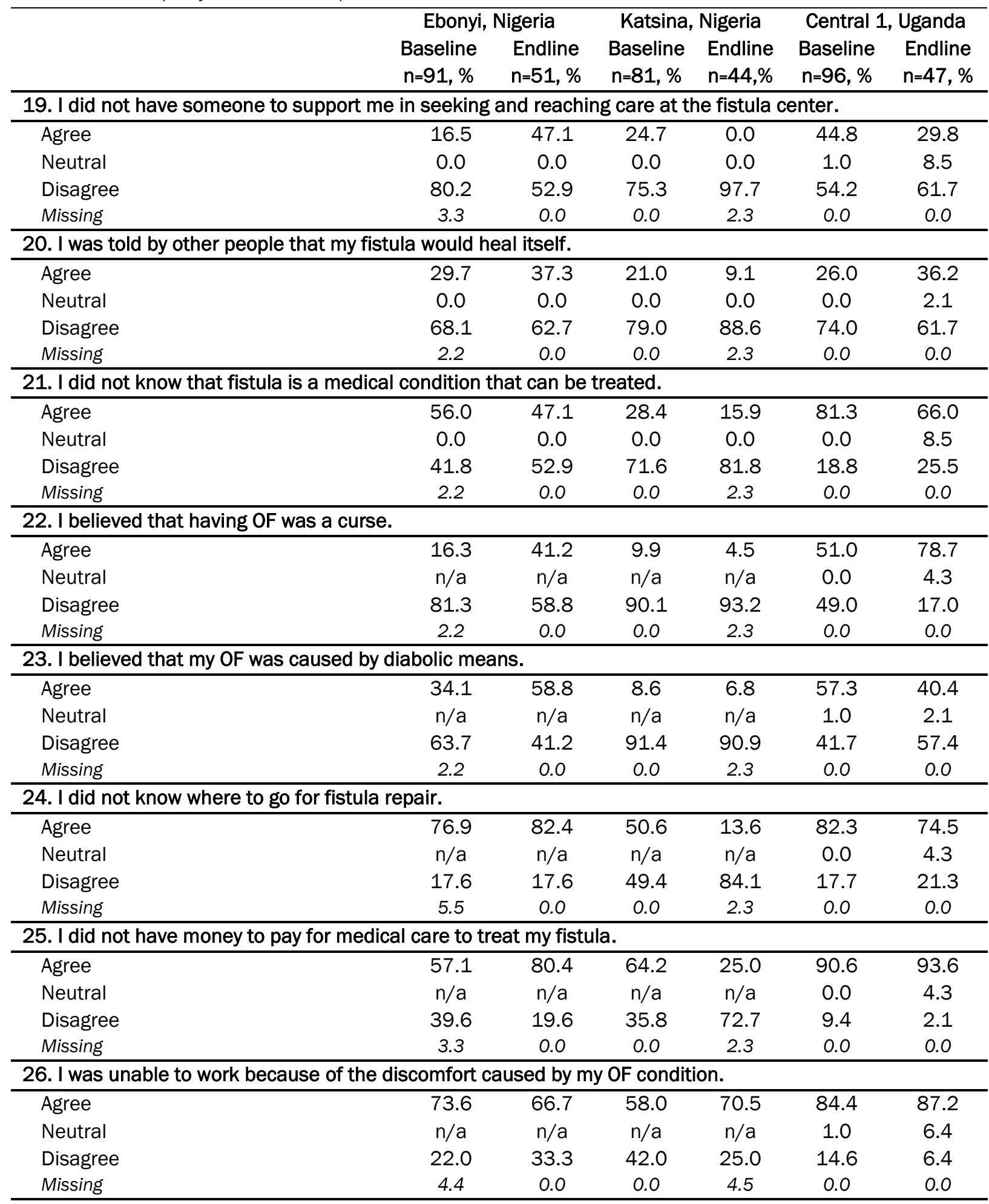




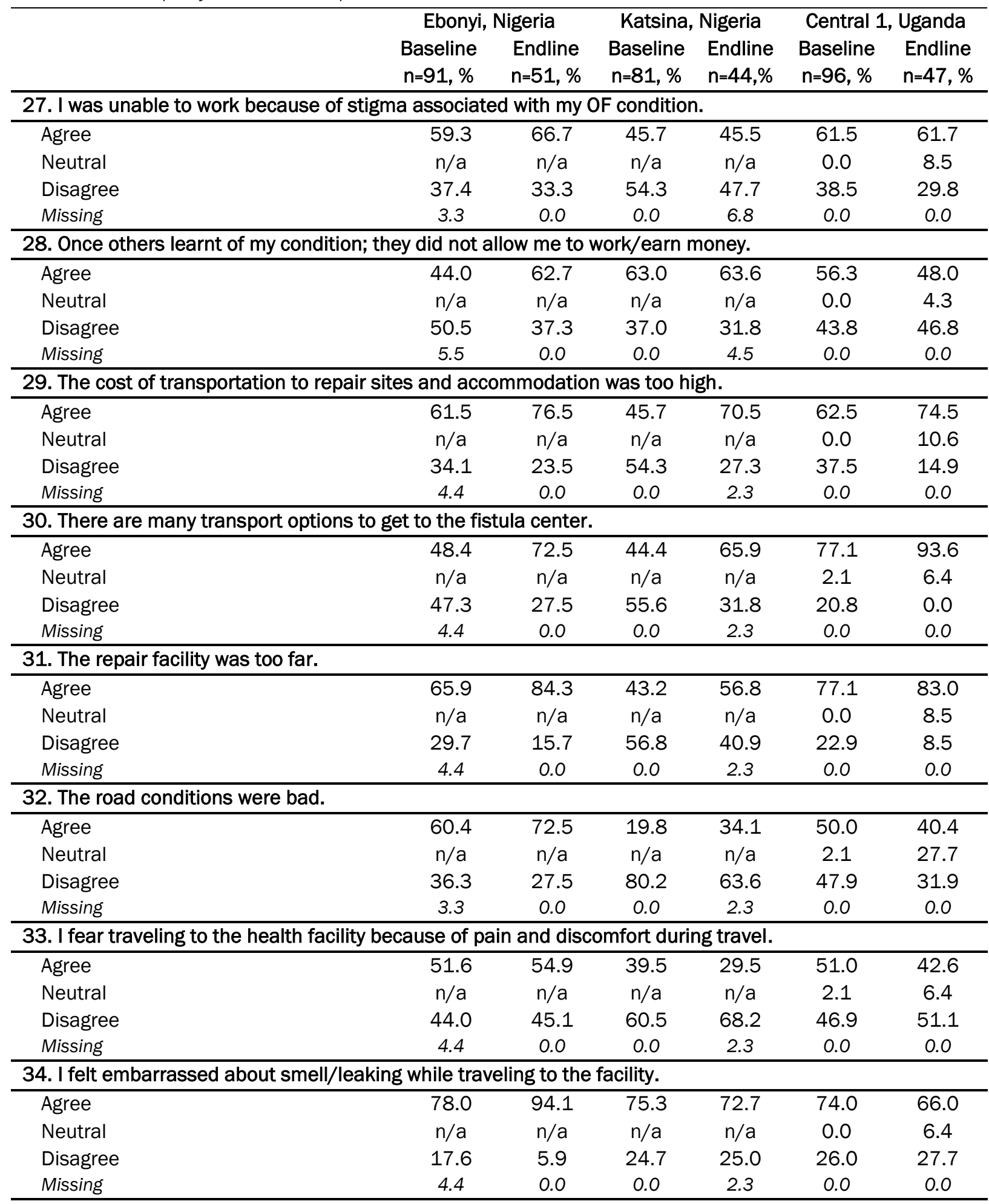




\begin{tabular}{|c|c|c|c|c|c|c|}
\hline & \multicolumn{2}{|c|}{ Ebonyi, Nigeria } & \multicolumn{2}{|c|}{ Katsina, Nigeria } & \multicolumn{2}{|c|}{ Central 1, Uganda } \\
\hline & $\begin{array}{l}\text { Baseline } \\
n=91, \%\end{array}$ & $\begin{array}{l}\text { Endline } \\
n=51, \%\end{array}$ & $\begin{array}{l}\text { Baseline } \\
n=81, \%\end{array}$ & $\begin{array}{l}\text { Endline } \\
n=44, \%\end{array}$ & $\begin{array}{l}\text { Baseline } \\
n=96, \%\end{array}$ & $\begin{array}{l}\text { Endline } \\
n=47, \%\end{array}$ \\
\hline \multicolumn{7}{|c|}{ 35. Repair facilities have enough doctors and nurses. } \\
\hline Agree & 90.1 & 94.1 & 96.3 & 79.5 & 88.5 & 97.9 \\
\hline Neutral & $\mathrm{n} / \mathrm{a}$ & $\mathrm{n} / \mathrm{a}$ & $\mathrm{n} / \mathrm{a}$ & $\mathrm{n} / \mathrm{a}$ & 0.0 & 2.1 \\
\hline Disagree & 4.4 & 5.9 & 3.7 & 18.2 & 11.5 & 0.0 \\
\hline Missing & 5.5 & 0.0 & 0.0 & 2.3 & 0.0 & 0.0 \\
\hline \multicolumn{7}{|c|}{ 36. I worried that there are not many female health workers at the facility. } \\
\hline Agree & 9.9 & 7.8 & 22.2 & 6.8 & 29.2 & 36.2 \\
\hline Neutral & $\mathrm{n} / \mathrm{a}$ & $\mathrm{n} / \mathrm{a}$ & $\mathrm{n} / \mathrm{a}$ & $\mathrm{n} / \mathrm{a}$ & 1.0 & 4.3 \\
\hline Disagree & 85.7 & 92.2 & 77.8 & 90.9 & 69.8 & 59.6 \\
\hline Missing & 4.4 & 0.0 & 0.0 & 2.3 & 0.0 & 0.0 \\
\hline \multicolumn{7}{|c|}{ 37. Facilities do not have electricity, equipment, or supplies to provide health services. } \\
\hline Agree & 17.6 & 9.8 & 1.2 & 9.1 & 14.6 & 8.5 \\
\hline Disagree & 79.1 & 90.2 & 98.8 & 88.6 & 85.4 & 91.5 \\
\hline Missing & 3.3 & 0.0 & 0.0 & 2.3 & 0.0 & 0.0 \\
\hline \multicolumn{7}{|c|}{ 38. I was afraid of harsh treatment by providers at the fistula center. } \\
\hline Agree & 20.5 & 19.6 & 23.5 & 15.9 & 50.0 & 40.4 \\
\hline Neutral & $\mathrm{n} / \mathrm{a}$ & $\mathrm{n} / \mathrm{a}$ & $\mathrm{n} / \mathrm{a} /$ & $\mathrm{n} / \mathrm{a}$ & 0.0 & 4.3 \\
\hline Disagree & 75.8 & 80.4 & 76.5 & 81.8 & 50.0 & 55.3 \\
\hline Missing & 3.3 & 0.0 & 0.0 & 2.3 & 0.0 & 0.0 \\
\hline \multicolumn{7}{|c|}{ 39. I did not want to stay for a long time at the fistula center to receive care. } \\
\hline Agree & 59.3 & 41.2 & 30.9 & 36.4 & 45.8 & 29.8 \\
\hline Neutral & $\mathrm{n} / \mathrm{a}$ & $\mathrm{n} / \mathrm{a}$ & $\mathrm{n} / \mathrm{a}$ & $\mathrm{n} / \mathrm{a}$ & 0.0 & 4.3 \\
\hline Disagree & 36.3 & 58.8 & 69.1 & 61.4 & 54.2 & 66.0 \\
\hline Missing & 4.4 & 0.0 & 0.0 & 2.3 & 0.0 & 0.0 \\
\hline \multicolumn{7}{|c|}{ 40. I was told by health providers (in the past) that my fistula will heal itself. } \\
\hline Agree & 20.9 & 15.7 & 6.2 & 0.0 & 7.3 & 17.0 \\
\hline Neutral & $\mathrm{n} / \mathrm{a}$ & $\mathrm{n} / \mathrm{a}$ & $\mathrm{n} / \mathrm{a}$ & $\mathrm{n} / \mathrm{a}$ & 0.0 & 4.3 \\
\hline Disagree & 75.8 & 84.3 & 92.6 & 97.7 & 92.7 & 78.7 \\
\hline Missing & 3.3 & 0.0 & 1.2 & 2.3 & 0.0 & 0.0 \\
\hline \multicolumn{7}{|c|}{ 41. I was told by health providers (in the past) that my fistula cannot be treated. } \\
\hline Agree & 15.4 & 5.9 & 7.4 & 2.3 & 8.3 & 10.6 \\
\hline Neutral & $\mathrm{n} / \mathrm{a}$ & $\mathrm{n} / \mathrm{a}$ & $\mathrm{n} / \mathrm{a}$ & $\mathrm{n} / \mathrm{a}$ & 0.0 & 6.4 \\
\hline Disagree & 80.2 & 94.1 & 91.4 & 95.5 & 91.7 & 83.0 \\
\hline Missing & 4.4 & 0.0 & 1.2 & 2.3 & 0.0 & 0.0 \\
\hline \multicolumn{7}{|c|}{ 42. When at other facilities for a different health condition, doctors and nurses did not treat me properly. } \\
\hline Agree & 29.7 & 11.8 & 24.7 & 18.2 & 35.4 & 38.4 \\
\hline Neutral & $\mathrm{n} / \mathrm{a}$ & $\mathrm{n} / \mathrm{a}$ & $\mathrm{n} / \mathrm{a}$ & $\mathrm{n} / \mathrm{a}$ & 2.1 & 2.1 \\
\hline Disagree & 61.5 & 88.2 & 74.1 & 75.0 & 62.5 & 59.6 \\
\hline Missing & 8.8 & 0.0 & 1.2 & 6.8 & 0.0 & 0.0 \\
\hline \multicolumn{7}{|c|}{ 43. Repair or treatments I had in the past did not work. } \\
\hline Agree & 20.9 & 13.7 & 25.9 & 18.2 & 53.1 & 18.1 \\
\hline Disagree & 46.2 & 86.3 & 30.9 & 4.5 & 46.9 & 0.0 \\
\hline Missing & 33.0 & 0.0 & 43.2 & 77.3 & 0.0 & 80.9 \\
\hline
\end{tabular}




\begin{tabular}{|c|c|c|c|c|c|c|c|c|c|c|c|c|}
\hline & \multicolumn{4}{|c|}{ Ebonyi, Nigeria } & \multicolumn{4}{|c|}{ Katsina, Nigeria } & \multicolumn{4}{|c|}{ Central 1, Uganda } \\
\hline & \multicolumn{2}{|c|}{ Intervention LGA } & \multicolumn{2}{|c|}{ Comparison LGA } & \multicolumn{2}{|c|}{ Intervention LGA } & \multicolumn{2}{|c|}{ Comparison LGA } & \multicolumn{2}{|c|}{ Intervention Dist. } & \multicolumn{2}{|c|}{ Comparison Dist. } \\
\hline & $\begin{array}{c}\text { Baseline } \\
n=44 \\
\%\end{array}$ & $\begin{array}{c}\text { Endline } \\
n=46 \\
\%\end{array}$ & $\begin{array}{c}\text { Baseline } \\
n=73 \\
\%\end{array}$ & $\begin{array}{c}\text { Endline } \\
n=54 \\
\%\end{array}$ & $\begin{array}{c}\text { Baseline } \\
n=42 \\
\%\end{array}$ & $\begin{array}{c}\text { Endline } \\
n=61 \\
\%\end{array}$ & $\begin{array}{c}\text { Baseline } \\
n=46 \\
\%\end{array}$ & $\begin{array}{c}\text { Endline } \\
n=32 \\
\%\end{array}$ & $\begin{array}{c}\text { Baseline } \\
n=57 \\
\%\end{array}$ & $\begin{array}{c}\text { Endline } \\
n=40 \\
\%\end{array}$ & $\begin{array}{c}\text { Baseline } \\
n=62 \\
\%\end{array}$ & $\begin{array}{c}\text { Endline } \\
\begin{array}{c}n=60 \\
\%\end{array}\end{array}$ \\
\hline \multicolumn{13}{|l|}{ Provider type } \\
\hline Medical officer & 6.8 & 6.5 & 6.8 & 5.6 & 9.5 & 3.3 & 2.2 & 0.0 & 0.0 & 0.0 & 3.2 & 1.7 \\
\hline Nurse/midwife & 9.1 & 15.2 & 21.9 & 14.8 & 28.6 & 27.9 & 6.5 & 18.8 & 14.0 & 0.0 & 6.5 & 5.0 \\
\hline CHEW & 75.0 & 71.7 & 54.8 & 68.5 & 38.1 & 54.1 & 50.0 & 71.9 & 64.9 & 87.5 & 59.7 & 66.7 \\
\hline $\mathrm{CHO}$ & 4.5 & 2.2 & 6.8 & 5.6 & 7.1 & 9.8 & 6.5 & 0.0 & 10.5 & 7.5 & 16.1 & 16.7 \\
\hline Nutritionist & 0.0 & 0.0 & 0.0 & 0.0 & 0.0 & 0.0 & 4.3 & 0.0 & 0.0 & 0.0 & 0.0 & 0.0 \\
\hline Social worker & 0.0 & 0.0 & 0.0 & 0.0 & 0.0 & 1.6 & 0.0 & 6.3 & 0.0 & 0.0 & 0.0 & 0.0 \\
\hline Other & 0.0 & 4.3 & 0.0 & 5.6 & 0.0 & 3.3 & 0.0 & 3.1 & 10.5 & 5.0 & 14.5 & 10.0 \\
\hline Missing & 4.5 & 0.0 & 9.6 & 0.0 & 16.7 & 0.0 & 30.4 & 0.0 & 0.0 & 0.0 & 0.0 & 0.0 \\
\hline \multicolumn{13}{|l|}{ Years as provider } \\
\hline Median & 10.0 & 11.0 & 6.0 & 10.0 & 18.0 & 18.0 & 9.5 & 10.0 & 5.0 & 5.0 & 5.0 & 5.0 \\
\hline IQR & $3-20.5$ & $6-23$ & $3-13$ & $5-18$ & $11-24$ & $8.5-24$ & $6-15$ & $5.5-18$ & $5-5$ & $5-5$ & $5-5$ & $5-5$ \\
\hline \multicolumn{13}{|c|}{ Received in-service training within year } \\
\hline Comprehensive ANC & 13.6 & 34.8 & 23.3 & 20.4 & 35.7 & 29.0 & 17.4 & 21.9 & 17.5 & 15.0 & 8.1 & 8.3 \\
\hline Management of labor & 22.7 & 56.5 & 35.6 & 46.3 & 38.1 & 31.2 & 10.9 & 9.4 & 21.1 & 32.5 & 8.1 & 13.3 \\
\hline $\begin{array}{l}\text { Active management of } 3^{\text {rd }} \\
\text { stage labor }\end{array}$ & 31.8 & 69.6 & 38.4 & 51.9 & 28.6 & 22.6 & 8.7 & 15.6 & 24.6 & 22.5 & 14.5 & 13.3 \\
\hline Partograph use & 22.7 & 69.6 & 31.5 & 59.3 & 26.2 & 30.1 & 13.0 & 18.8 & 26.3 & 42.5 & 16.1 & 13.3 \\
\hline Essential newborn care & 34.1 & 71.7 & 43.8 & 72.2 & 42.9 & 26.9 & 17.4 & 28.1 & 33.3 & 30.0 & 21.0 & 10.0 \\
\hline Newborn resuscitation & 34.1 & 73.9 & 46.6 & 68.5 & 31.0 & 32.3 & 4.3 & 25.0 & 33.3 & 30.0 & 22.6 & 13.3 \\
\hline Special newborn care & 15.9 & 58.7 & 30.1 & 42.6 & 26.2 & 24.7 & 4.3 & 21.9 & 19.3 & 20.0 & 11.3 & 10.0 \\
\hline Comprehensive PNC & 13.6 & 47.8 & 21.9 & 22.2 & 26.2 & 17.2 & 8.7 & 18.8 & 15.8 & 20.0 & 6.5 & 6.7 \\
\hline Eclampsia management & 27.3 & 71.7 & 34.2 & 59.3 & 40.5 & 29.0 & 15.2 & 28.1 & 19.3 & 20.0 & 16.1 & 10.0 \\
\hline Magnesium sulphate & 20.5 & 71.1 & 28.8 & 51.9 & 45.2 & 30.1 & 23.9 & 25.0 & 17.5 & 15.0 & 16.1 & 10.0 \\
\hline \multicolumn{13}{|l|}{ Management of: } \\
\hline High blood pressure & 18.2 & 56.5 & 26.0 & 50.0 & 35.7 & 30.1 & 10.9 & 28.1 & 24.6 & 17.5 & 11.3 & 10.0 \\
\hline Sepsis/infection & 11.4 & 39.1 & 21.9 & 51.9 & 21.4 & 21.5 & 2.2 & 15.6 & 19.3 & 17.5 & 8.1 & 8.3 \\
\hline Obstructed labor & 15.9 & 34.8 & 23.3 & 27.8 & 14.3 & 21.5 & 0.0 & 12.5 & 17.5 & 22.5 & 8.1 & 8.3 \\
\hline Family planning & 65.9 & 63.0 & 50.7 & 46.3 & 38.1 & 46.2 & 13.0 & 46.9 & 26.3 & 35.0 & 27.4 & 41.7 \\
\hline None & 0.0 & 8.7 & 0.0 & 3.7 & 0.0 & 7.5 & 0.0 & 25.0 & 29.8 & 45.0 & 40.3 & 43.3 \\
\hline
\end{tabular}


Table A10. PHC provider knowledge of and practices around prolonged / obstructed labor and genital fistula

\begin{tabular}{|c|c|c|c|c|c|c|c|c|c|c|c|c|}
\hline & \multicolumn{4}{|c|}{$\begin{array}{l}\text { Ebonyi, Nigeria } \\
\end{array}$} & \multicolumn{4}{|c|}{ Katsina, Nigeria } & \multicolumn{4}{|c|}{ Central 1, Uganda } \\
\hline & \multicolumn{2}{|c|}{ Intervention LGA } & \multicolumn{2}{|c|}{ Comparison LGA } & \multicolumn{2}{|c|}{ Intervention LGA } & \multicolumn{2}{|c|}{ Comparison LGA } & \multicolumn{2}{|c|}{ Intervention District } & \multicolumn{2}{|c|}{ Comparison District } \\
\hline & $\begin{array}{c}\text { Baseline } \\
n=44 \\
\%\end{array}$ & $\begin{array}{c}\text { Endline } \\
n=46 \\
\%\end{array}$ & $\begin{array}{c}\text { Baseline } \\
n=73 \\
\%\end{array}$ & $\begin{array}{c}\text { Endline } \\
\begin{array}{c}n=54 \\
\%\end{array}\end{array}$ & $\begin{array}{c}\text { Baseline } \\
n=42 \\
\%\end{array}$ & $\begin{array}{c}\text { Endline } \\
\begin{array}{c}n=61 \\
\%\end{array}\end{array}$ & $\begin{array}{c}\text { Baseline } \\
n=46 \\
\%\end{array}$ & $\begin{array}{c}\text { Endline } \\
\begin{array}{c}n=32 \\
\%\end{array}\end{array}$ & $\begin{array}{c}\text { Baseline } \\
\mathrm{n}=57 \\
\%\end{array}$ & $\begin{array}{c}\text { Endline } \\
\begin{array}{c}n=40 \\
\%\end{array}\end{array}$ & $\begin{array}{c}\text { Baseline } \\
n=62 \\
\%\end{array}$ & $\begin{array}{c}\text { Endline } \\
\mathrm{n}=60 \\
\%\end{array}$ \\
\hline \multicolumn{13}{|c|}{ Providers who cited following to avoid fistula (missing) } \\
\hline $\begin{array}{l}\text { Monitor labor closely } \\
\text { (partograph) }\end{array}$ & 54.5 & $\begin{array}{c}56.5 \\
(32.6)\end{array}$ & 34.2 & $\begin{array}{l}51.9 \\
(16.7)\end{array}$ & 92.9 & $\begin{array}{l}45.9 \\
(39.3)\end{array}$ & 63.0 & $\begin{array}{c}43.8 \\
(31.3)\end{array}$ & 75.4 & 80.0 & 72.6 & 46.7 \\
\hline Detect prolonged labor & 52.3 & $\begin{array}{l}54.3 \\
(30.4)\end{array}$ & 39.7 & $\begin{array}{c}40.7 \\
(14.8)\end{array}$ & 40.5 & $\begin{array}{c}62.3 \\
(26.2)\end{array}$ & 58.7 & $\begin{array}{c}46.9 \\
(34.4)\end{array}$ & 82.5 & 85.0 & 82.3 & 56.7 \\
\hline $\begin{array}{l}\text { Avoid obstructed labor/C- } \\
\text { section }\end{array}$ & 47.7 & $\begin{array}{l}54.3 \\
(34.8)\end{array}$ & 35.6 & $\begin{array}{c}48.1 \\
(14.8)\end{array}$ & 57.1 & $\begin{array}{c}45.9 \\
(34.4)\end{array}$ & 41.3 & $\begin{array}{l}21.9 \\
(50.0)\end{array}$ & 28.1 & 35.0 & 27.4 & 10.0 \\
\hline $\begin{array}{l}\text { In-dwelling urine catheter for } \\
\text { 5-7 days }\end{array}$ & 56.8 & $\begin{array}{r}34.8 \\
(54.3) \\
\end{array}$ & 60.3 & $\begin{array}{c}25.9 \\
(27.8) \\
\end{array}$ & 2.4 & $\begin{array}{c}14.8 \\
(50.8)\end{array}$ & 4.3 & $\begin{array}{c}9.4 \\
(59.4)\end{array}$ & 19.3 & 42.5 & 12.9 & 18.3 \\
\hline \multicolumn{13}{|c|}{ Providers cited following to prevent fistula (missing) } \\
\hline Family planning & 38.6 & $\begin{array}{c}19.6 \\
(58.7)\end{array}$ & 20.5 & $\begin{array}{c}18.5 \\
(33.3)\end{array}$ & 73.8 & $\begin{array}{l}47.5 \\
(29.5)\end{array}$ & 67.4 & $\begin{array}{c}25.0 \\
(53.1)\end{array}$ & 10.5 & 52.5 & 22.6 & 21.7 \\
\hline $\begin{array}{l}\text { Management of labor using } \\
\text { partograph }\end{array}$ & 40.9 & $\begin{array}{c}43.5 \\
(41.3)\end{array}$ & 24.7 & $\begin{array}{l}31.5 \\
(22.2)\end{array}$ & 52.4 & $\begin{array}{c}41.0 \\
(42.6)\end{array}$ & 52.2 & $\begin{array}{l}25.0 \\
(56.3)\end{array}$ & 57.9 & 75.0 & 66.1 & 35.0 \\
\hline Skilled attendance at delivery & 86.4 & $\begin{array}{c}69.6 \\
(26.1)\end{array}$ & 75.3 & $\begin{array}{c}55.6 \\
(20.4)\end{array}$ & 42.9 & $\begin{array}{c}42.6 \\
(39.3)\end{array}$ & 50.0 & $\begin{array}{l}40.6 \\
(43.8)\end{array}$ & 71.9 & 100.0 & 82.3 & 80.0 \\
\hline Emergency obstetric care & 27.3 & $\begin{array}{l}10.9 \\
(60.9)\end{array}$ & 13.7 & $\begin{array}{c}7.4 \\
(35.2)\end{array}$ & 19.0 & $\begin{array}{c}18.0 \\
(49.2)\end{array}$ & 17.4 & $\begin{array}{c}9.4 \\
(56.3)\end{array}$ & 26.3 & 52.5 & 16.1 & 16.7 \\
\hline Don't Know & 4.5 & $\begin{array}{c}0.0 \\
(69.6)\end{array}$ & 4.1 & $\begin{array}{c}7.4 \\
(33.3)\end{array}$ & 0.0 & $\begin{array}{c}0.0 \\
(59.0)\end{array}$ & 0.0 & $\begin{array}{c}3.1 \\
(59.4)\end{array}$ & 29.8 & 0.0 & 16.1 & 26.7 \\
\hline \multicolumn{13}{|c|}{ Providers cited following social issues to address fistula (missing) } \\
\hline Early pregnancy & 72.7 & $\begin{array}{c}56.5 \\
(34.8)\end{array}$ & 41.1 & $\begin{array}{c}40.7 \\
(22.2)\end{array}$ & 81.0 & $\begin{array}{l}52.5 \\
(37.7)\end{array}$ & 69.6 & $\begin{array}{c}40.6 \\
(40.6)\end{array}$ & 43.9 & 95.0 & 45.2 & 21.7 \\
\hline Early marriage & 54.5 & $\begin{array}{l}37.0 \\
(50.0)\end{array}$ & 46.6 & $\begin{array}{c}44.4 \\
(18.5)\end{array}$ & 83.3 & $\begin{array}{l}75.4 \\
(18.0)\end{array}$ & 93.5 & $\begin{array}{l}68.8 \\
(28.1)\end{array}$ & 40.4 & 82.5 & 51.6 & 26.7 \\
\hline Girls' illiteracy & 38.6 & $\begin{array}{c}30.4 \\
(52.2)\end{array}$ & 35.6 & $\begin{array}{l}31.5 \\
(24.1)\end{array}$ & 45.2 & $\begin{array}{l}26.2 \\
(41.0)\end{array}$ & 50.0 & $\begin{array}{l}34.4 \\
(40.6)\end{array}$ & 22.8 & 72.5 & 25.8 & 11.7 \\
\hline Poverty & 36.4 & $\begin{array}{c}15.2 \\
(58.7)\end{array}$ & 17.8 & $\begin{array}{c}24.1 \\
(25.9)\end{array}$ & 11.9 & $\begin{array}{c}47.5 \\
(36.1)\end{array}$ & 19.6 & $\begin{array}{c}25.0 \\
(50.0)\end{array}$ & 26.3 & 57.5 & 29.0 & 31.7 \\
\hline Women's lack of power & 13.6 & $\begin{array}{c}10.9 \\
(58.7)\end{array}$ & 5.5 & $\begin{array}{c}9.3 \\
(33.3)\end{array}$ & 11.9 & $\begin{array}{c}21.3 \\
(47.5)\end{array}$ & 2.2 & $\begin{array}{c}15.6 \\
(53.1)\end{array}$ & 14 & 47.5 & 19.4 & 21.7 \\
\hline Don't know & 0.0 & $\begin{array}{c}0.0 \\
(67.4)\end{array}$ & 1.4 & $\begin{array}{l}13.0 \\
(33.3)\end{array}$ & 0.0 & $\begin{array}{c}3.3 \\
(57.4)\end{array}$ & 0.0 & $\begin{array}{c}3.1 \\
(62.5)\end{array}$ & 22.8 & 0.0 & 22.6 & 0.0 \\
\hline
\end{tabular}


Figure A1. PHC providers' knowledge change about fistula causes and symptoms (\%) in Ebonyi, Nigeria

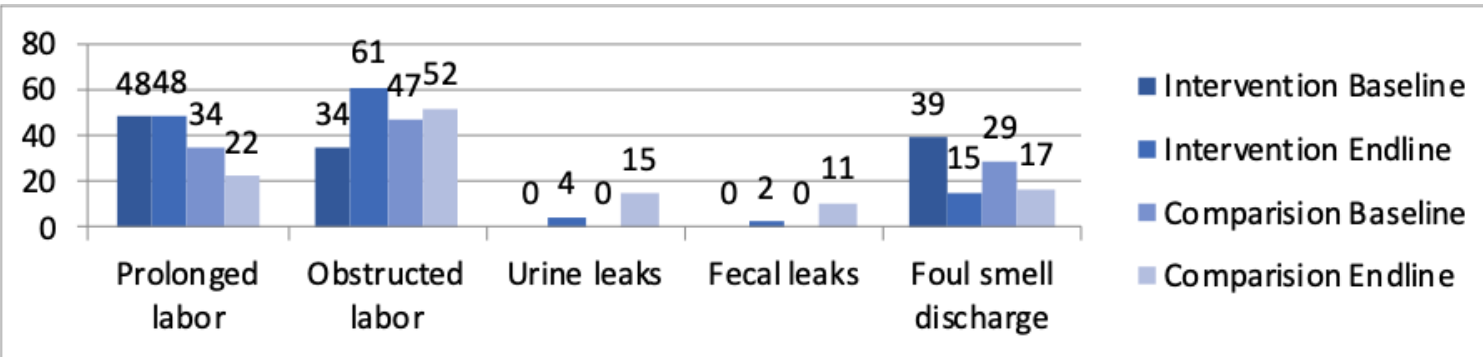

Figure A2. PHC providers' knowledge change about fistula causes and symptoms (\%) in Katsina, Nigeria

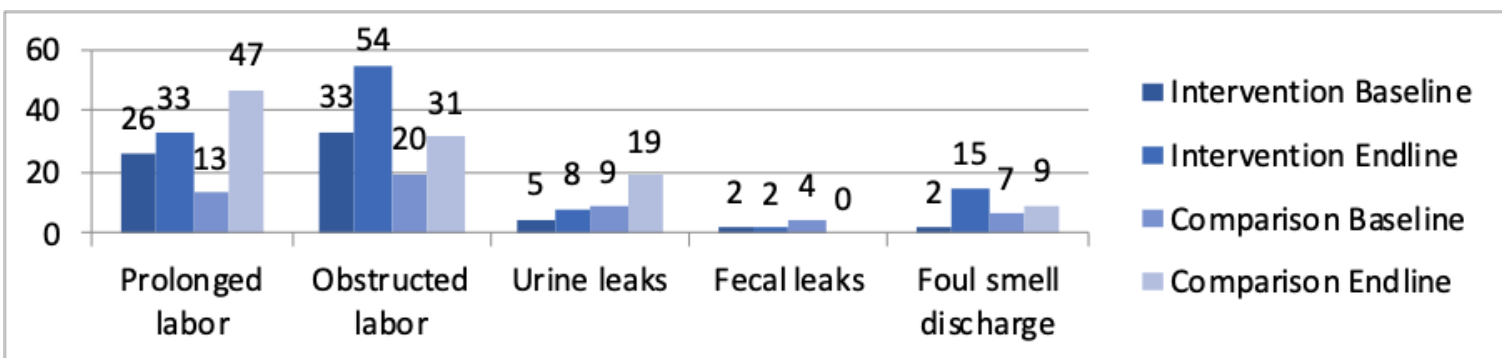

Figure A3. PHC providers' knowledge change about fistula causes and symptoms (\%) in Central-1 sub-Region, Uganda

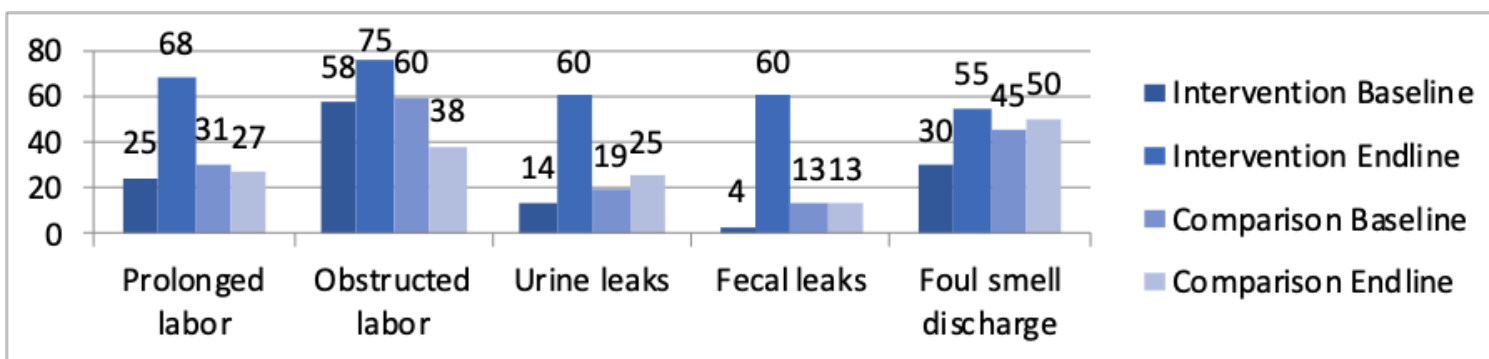

